LIMAS TOMIO, Fabrício Ricardo de; ROBL FILHO, Ilton Norberto. Autonomia e prerrogativas do ministério público brasileiro em perspectiva comparada: construindo um índice de independência/autonomia. Revista Eletrônica Direito e Política, Programa de Pós-Graduação Stricto Sensu em Ciência Jurídica da UNIVALI, Itajaí, v.16, n.3, 30 quadrimestre de 2021. Disponível em: www.univali.br/direitoepolitica - ISSN 1980-7791.

\title{
AUTONOMIA E PRERROGATIVAS DO MINISTÉRIO PÚBLICO BRASILEIRO EM PERSPECTIVA COMPARADA: CONSTRUINDO UM ÍNDICE DE INDEPENDÊNCIA/AUTONOMIA
}

\author{
AUTONOMY AND PREROGATIVES OF THE BRAZILIAN PUBLIC PROSECUTOR'S \\ OFFICE IN A COMPARATIVE PERSPECTIVE: BUILDING AN \\ INDEPENDENCE/AUTONOMY INDEX
}

Fabrício Ricardo de Limas Tomio

Ilton Norberto Robl Filho

\section{RESUMO}

A constatação do elevado grau de autonomia e independência do Ministério Público (MP) brasileiro (após Constituição Federal/1988) tem sido frequente na literatura nacional e comparada. Este artigo tem por objetivo principal desenvolver um índice para mensurar a autonomia e a independência do MP, permitindo uma análise comparada mais precisa do MP brasileiro com outras instituições semelhantes no mundo. Secundariamente, comparamos o índice do MP aos outros poderes constitucionais (Legislativo, Executivo e Judiciário) para dimensionar a relação entre os poderes e, eventualmente, sugerir uma explicação causal (constitutional making) para a independência/autonomia atribuída constitucional e estatutariamente ao MP. Como metodologia, inicialmente, utilizamos índices consolidados na literatura que analisam os poderes constitucionais do Estado (CCP Índices). Em seguida, abordando o objeto central, descrevemos e construímos um índice de independência/autonomia do MP (CEPEJ/DIRPOL) com base em prerrogativas institucionais (de jure), compilando a legislação brasileira e utilizando os dados organizados pelo CEPEJ para 47 países europeus. Os achados e conclusões preliminares demonstram que o Brasil apresenta quase todas as prerrogativas e garantias atribuídas ao MP de forma plena, situando-se no estrato mais elevado do índice, e, comparativamente, reforçam a percepção, estatisticamente limitada, que há maior probabilidade de encontrar um grau mais elevado de prerrogativas e garantias institucionais atribuídas ao MP em países que constitucionalizam mais poderes ao Legislativo ou em "democracias recentes" (transições mais recentes de regimes autoritários).

\footnotetext{
1 Professor Titular da Faculdade de Direito da Universidade Federal do Paraná (UFPR). Coordenador do Programa de Pós-Graduação (Mestrado, Doutorado e Pós-Doutorado) da UFPR. Doutor em Ciência Política pela Universidade Estadual de Campinas (UNICAMP). E-mail: fab_tom@hotmail.com.

2 Professor Adjunto da Faculdade de Direito da UFPR e do Mestrado e Doutorado do Instituto Brasileiro de Ensino, Desenvolvimento e Pesquisa (IDP-Brasília). Realizou Pós-Doutorado em Direito Constitucional na Pontifícia Universidade Católica do Rio Grande do Sul (PUC/RS). Doutor em Direito pela UFPR. Coordenador de Pesquisa da Academia Brasileira de Direito Constitucional (ABDConst). E-mail: norbertorobl@gmail.com.
} 
LIMAS TOMIO, Fabrício Ricardo de; ROBL FILHO, Ilton Norberto. Autonomia e prerrogativas do ministério público brasileiro em perspectiva comparada: construindo um índice de independência/autonomia. Revista Eletrônica Direito e Política, Programa de Pós-Graduação Stricto Sensu em Ciência Jurídica da UNIVALI, Itajaí, v.16, n.3, 30 quadrimestre de 2021. Disponível em: www.univali.br/direitoepolitica - ISSN 1980-7791.

PALAVRAS-CHAVE: Ministério Público; Autonomia; Prerrogativa; Índice.

\section{ABSTRACT}

The finding of the high degree of autonomy and independence of the Brazilian Public Prosecutors (after the Federal Constitution of 1988) has been frequent in the national and comparative specialized literature. The main objective of this article is to develop an index to measure the autonomy and independence of the Public Prosecutor, for a more accurate comparative analysis of the Brazilian Public Prosecutor's Office with other similar institutions in the world. Secondarily, we compare the index of the Public Prosecutor to other constitutional powers (Legislative, Executive and Judiciary) to assess the relationship between the powers and, eventually, suggest a causal explanation (constitutional making) for the independence/autonomy attributed, constitutional and statutorily, to the Public Prosecutor. As a methodology, initially, we used indexes consolidated in the literature that analyze the constitutional powers of the State (CCP Indexes). Then, approaching the central object, we describe and make the index of independence/autonomy of the Public Prosecutor (CEPEJ/DIRPOL) based on institutional prerogatives (de jure) and on Brazilian legislation and using data organized by CEPEJ for 47 European countries. Preliminary findings and conclusions: demonstrate that Brazil has almost all the prerogatives and guarantees attributed to the Public Prosecutor in full, standing in the highest stratum of the index, and, comparatively, reinforce the (statistically limited) perception that there is a greater probability of finding a higher degree of institutional prerogatives and guarantees attributed to the Public Prosecutor in countries that constitutionalize more powers to the Legislative or in "recent democracies" (more recent transitions of regimes authoritarian).

KEYWORDS: Public Prosecutor; Autonomy; Prerogative; Index.

\section{INTRODUÇÃO}

Este artigo tem por objetivo principal desenvolver um índice para mensurar a autonomia e a independência do Ministério Público, permitindo uma análise comparada mais precisa do Ministério Público brasileiro com outras instituições estatais semelhantes no mundo.

Os principais indicadores comparados existentes não são diretamente relacionados ao Ministério Público, mas servirão para dimensionar, dentro de um país, a relação 
LIMAS TOMIO, Fabrício Ricardo de; ROBL FILHO, Ilton Norberto. Autonomia e prerrogativas do ministério público brasileiro em perspectiva comparada: construindo um índice de independência/autonomia. Revista Eletrônica Direito e Política, Programa de Pós-Graduação Stricto Sensu em Ciência Jurídica da UNIVALI, Itajaí, v.16, n.3, 30 quadrimestre de 2021. Disponível em: www.univali.br/direitoepolitica - ISSN 1980-7791.

entre os poderes e, eventualmente, sugerir uma explicação causal (constitutional making) para a independência/autonomia do MP. Além disto, pela abrangência da comparação dos índices do CCP (Comparative Constitutions Project) foi possível constatar indireta e comparativamente, como hipótese (pelo proxy de Judicial Independence), a elevada autonomia institucional e constitucional do Ministério Público brasileiro, pois a estrutura constitucional do Judiciário brasileiro é semelhante ao do Ministério Público.

Dessa forma, nos itens 2 e 3 deste texto, serão expostos e correlacionados os índices comparativos sobre o Executivo, o Legislativo e o Judiciário a partir do Comparative Constitutions Project. De outro lado, a seção 4 versa acerca das características institucionais do Ministério Público brasileiro, analisando ainda os índices existentes sobre o Ministério Público. Ainda, nessa seção, será construído um índice para analisar o Ministério Público brasileiro em diálogo e desde a metodologia estabelecida pela Comissão Europeia para Eficiência do Judiciário (CEPEJ).

O item 5, por sua vez, apresenta correlações entre os poderes do Executivo e Legislativo e a Independência do Judiciário com a independência e com a autonomia do Ministério Público. Por fim, nesse item, é escrutinada a relação entre autonomia do Ministério Público com o restabelecimento da democracia após governos e Estados autoritários. Na seção 6, as conclusões são apresentadas.

\section{QUESTÕES PRELIMINARES: ÍNDICES COMPARATIVOS DE INDEPENDÊNCIA DO JUDICIÁRIO E DAS COMPETÊNCIAS E DOS PODERES DO EXECUTIVO E DO LEGISLATIVO A PARTIR ESPECIALMENTE DO COMPARATIVE CONSTITUTIONS PROJECT - CCP}

Os índices comparativos sobre instituições estatais, os quais buscam mensurar, por exemplo, os poderes, a independência, a autonomia, são derivados de aspectos institucionais como distribuição de competências e prerrogativas atribuídas a esses 
LIMAS TOMIO, Fabrício Ricardo de; ROBL FILHO, Ilton Norberto. Autonomia e prerrogativas do ministério público brasileiro em perspectiva comparada: construindo um índice de independência/autonomia. Revista Eletrônica Direito e Política, Programa de Pós-Graduação Stricto Sensu em Ciência Jurídica da UNIVALI, Itajaí, v.16, n.3, 30 quadrimestre de 2021. Disponível em: www.univali.br/direitoepolitica - ISSN 1980-7791.

atores institucionais (poderes constitucionais e demais instituições de Estado), por meio da constituição e/ou da legislação. Dessa forma, permite-se estimar e mensurar os efeitos da variação institucional no processo decisório, na relação entre os poderes estatais e órgãos constitucionais autônomos e na formulação das políticas públicas. Esses índices comparativos estabelecem associações e explicações (causalidade) sobre as intenções dos constituintes (Poder Constituinte Originário e Poder Constituinte Derivado Reformador) ao atribuir graus distintos de competências/prerrogativas a cada poder, a órgão constitucional autônomo e para as demais instituições estatais.

Dessa forma, para construir um índice comparativo de autonomia/independência do Ministério Público (Prosecutorial Independence - PI - de jure), estabelecendo o status do Ministério Público brasileiro, serão observadas as seguintes etapas. Em primeiro lugar, impõe-se compreender a situação das outras instituições centrais do Estado (no mesmo país e entre os países comparados). Em segundo lugar, analisar-se-ão os índices (de jure) mais consolidados na literatura sobre instituições, órgãos e poderes estatais, buscando posteriormente elaborar um índice próprio sobre o Ministério Público para descrever e analisar, comparativamente, o grau de autonomia/independência do Ministério Público no Brasil.

Dentre o conjunto de índices comparados, observa-se o construído especialmente pelos pesquisadores Zachary Elkins, Tom Ginsburg e James Melton, no Comparative Constitutions Project-CCP, reunindo indicadores extraídos diretamente do texto constitucional de 190 países e sendo os índices mais abrangentes ${ }^{3}$. Os três índices

${ }^{3}$ ELKINS, Zachary; GINSBURG, Tom; MELTON, James. The comparative constitutions project: A cross-national historical dataset of written constitutions. Chicago: Mimeo, 2009a. ELKINS, Zachary; GINSBURG, Tom; MELTON, James. The endurance of national constitutions. CambridgeUK: Cambridge University Press, 2009b. ELKINS, Zachary; GINSBURG, Tom; MELTON, James. Constitutional constraints on executive lawmaking. Working paper, 2012. Disponível em: http://citeseerx.ist.psu.edu/viewdoc/summary?doi=10.1.1.434.9346. Acesso em 11.10.2021. FISH, M. Steven; KROENIG, Matthew. The handbook of national legislatures: A global survey. CambridgeUK: Cambridge University Press, 2009. MELTON, James; GINSBURG, Tom. Does de jure judicial independence really matter? A reevaluation of explanations for judicial independence. Journal of Law and Courts, v. 2, n. 2, p. 187-217, 2014. 
LIMAS TOMIO, Fabrício Ricardo de; ROBL FILHO, Ilton Norberto. Autonomia e prerrogativas do ministério público brasileiro em perspectiva comparada: construindo um índice de independência/autonomia. Revista Eletrônica Direito e Política, Programa de Pós-Graduação Stricto Sensu em Ciência Jurídica da UNIVALI, Itajaí, v.16, n.3, 30 quadrimestre de 2021. Disponível em: www.univali.br/direitoepolitica - ISSN 1980-7791.

(Executive Power, Legislative Power e Judicial Independence) são extraídos do CCP Data (descritos na página da web do CCP). ${ }^{4}$ Para a utilização nesta análise, inclusive por considerações qualitativas, o ranking e os indicadores contínuos são tratados como classes e separatrizes, dividindo o intervalo de frequência da amostra em partes iguais (tercis, metade) e agrupando países pelo valor atribuído pelo índice.

No caso brasileiro, em virtude especialmente dos artigos 127, §§ 20, $3^{\circ}$ e 40 e 128, §§ $5^{\circ}$ e 60, Constituição Federal brasileira de $1988(\mathrm{CF} / 88)^{5}$, o índice de Independência Judicial (Judicial Independence, CCP) poderia ser tratado como proxy (substituto) da Independência/Autonomia do Ministério Público (MP). Em outras palavras, as autonomias funcional, administrativa e financeira garantidas constitucionalmente ao MP do Brasil (art. 127, §§ 20, $3^{\circ}$ e 40, CF/88) podem ser

${ }^{4}$ Além dos três índices (Executive Power, Legislative Power e Judicial Independence), o Comparative Constitutions Project - CCP (índices) apresenta outros três indicadores comparativos: Scope (mede a porcentagem de 70 tópicos principais da pesquisa do CCP que estão incluídos em qualquer constituição), Length in Words (relatório do número total de palavras em cada constituição) e Number of Rights (sobre direitos humanos, um conjunto de 117 direitos específicos encontrados nas constituições nacionais) (ELKINS, GINSBURG e MELTON, 2009a).

5 "§ $2^{\circ}$ Ao Ministério Público é assegurada autonomia funcional e administrativa, podendo, observado o disposto no art. 169, propor ao Poder Legislativo a criação e extinção de seus cargos e serviços auxiliares, provendo-os por concurso público de provas ou de provas e títulos, a política remuneratória e os planos de carreira; a lei disporá sobre sua organização e funcionamento. (Redação dada pela Emenda Constitucional n 19, de 1998) § $3^{\circ}$ O Ministério Público elaborará sua proposta orçamentária dentro dos limites estabelecidos na lei de diretrizes orçamentárias. § $4^{\circ}$ Se o Ministério Público não encaminhar a respectiva proposta orçamentária dentro do prazo estabelecido na lei de diretrizes orçamentárias, o Poder Executivo considerará, para fins de consolidação da proposta orçamentária anual, os valores aprovados na lei orçamentária vigente, ajustados de acordo com os limites estipulados na forma do $\S$ $3^{\circ}$. (Incluído pela Emenda Constitucional no 45, de 2004) (...) § $5^{\circ}$ Leis complementares da União e dos Estados, cuja iniciativa é facultada aos respectivos Procuradores-Gerais, estabelecerão a organização, as atribuições e o estatuto de cada Ministério Público, observadas, relativamente a seus membros: I as seguintes garantias: a) vitaliciedade, após dois anos de exercício, não podendo perder o cargo senão por sentença judicial transitada em julgado; b) inamovibilidade, salvo por motivo de interesse público, mediante decisão do órgão colegiado competente do Ministério Público, pelo voto da maioria absoluta de seus membros, assegurada ampla defesa; (Redação dada pela Emenda Constitucional no 45, de 2004) c) irredutibilidade de subsídio, fixado na forma do art. 39, § 40, e ressalvado o disposto nos arts. 37, X e XI, 150, II, 153, III, 153, § 20, I; (Redação dada pela Emenda Constitucional no 19, de 1998) II - as seguintes vedações: a) receber, a qualquer título e sob qualquer pretexto, honorários, percentagens ou custas processuais; b) exercer a advocacia; c) participar de sociedade comercial, na forma da lei; d) exercer, ainda que em disponibilidade, qualquer outra função pública, salvo uma de magistério; e) exercer atividade político-partidária; (Redação dada pela Emenda Constitucional no 45, de 2004); f) receber, a qualquer título ou pretexto, auxílios ou contribuições de pessoas físicas, entidades públicas ou privadas, ressalvadas as exceções previstas em lei. (Incluída pela Emenda Constitucional no 45, de 2004) § $6^{\circ}$ Aplica-se aos membros do Ministério Público o disposto no art. 95, parágrafo único, V. (Incluído pela Emend Constitucional no 45, de 2004)". 
LIMAS TOMIO, Fabrício Ricardo de; ROBL FILHO, Ilton Norberto. Autonomia e prerrogativas do ministério público brasileiro em perspectiva comparada: construindo um índice de independência/autonomia. Revista Eletrônica Direito e Política, Programa de Pós-Graduação Stricto Sensu em Ciência Jurídica da UNIVALI, Itajaí, v.16, n.3, 30 quadrimestre de 2021. Disponível em: www.univali.br/direitoepolitica - ISSN 1980-7791.

comparadas e dimensionadas à independência judicial garantida no artigo 99, CF/88 ${ }^{6}$. Acerca das garantias funcionais, tanto na magistratura como no Ministério Público, há as garantias da vitaliciedade, inamovibilidade e irredutibilidade, segundo os artigos 95, I, II e III $^{7}$ e 128, $\S 50$, I, CF/88. De outro lado, uma diferença constitucional relevante brasileira consiste na escolha do chefe do Ministério Público da União que é nomeado pelo Presidente da República, após a sabatina do Senado Federal, e na escolha dos Chefes dos Ministérios Públicos dos Estados e do Distrito Federal, os quais escolhidos pelo Governador, a partir de lista tríplice dentre os membros da carreira, de acordo com o artigo 128 , $\S \S 1^{\circ}$ e $3^{\circ}, C F / 88^{8}$, enquanto compete aos tribunais "a) eleger seus órgãos diretivos e elaborar seus regimentos internos, com observância das normas de processo e das garantias processuais das partes, dispondo sobre a

6 "Art. 99. Ao Poder Judiciário é assegurada autonomia administrativa e financeira. $\S 10$ Os tribunais elaborarão suas propostas orçamentárias dentro dos limites estipulados conjuntamente com os demais Poderes na lei de diretrizes orçamentárias. § $2^{\circ} \mathrm{O}$ encaminhamento da proposta, ouvidos os outros tribunais interessados, compete: I - no âmbito da União, aos Presidentes do Supremo Tribunal Federal e dos Tribunais Superiores, com a aprovação dos respectivos tribunais; II - no âmbito dos Estados e no do Distrito Federal e Territórios, aos Presidentes dos Tribunais de Justiça, com a aprovação dos respectivos tribunais. § $3^{\circ}$ Se os órgãos referidos no $\S 2^{\circ}$ não encaminharem as respectivas propostas orçamentárias dentro do prazo estabelecido na lei de diretrizes orçamentárias, o Poder Executivo considerará, para fins de consolidação da proposta orçamentária anual, os valores aprovados na lei orçamentária vigente, ajustados de acordo com os limites estipulados na forma do $\S 10$ deste artigo. (Incluído pela Emenda Constitucional no 45, de 2004) $\S 4^{\circ}$ Se as propostas orçamentárias de que trata este artigo forem encaminhadas em desacordo com os limites estipulados na forma do $\S$ 10 , o Poder Executivo procederá aos ajustes necessários para fins de consolidação da proposta orçamentária anual. (Incluído pela Emenda Constitucional no 45, de 2004) § $5^{\circ}$ Durante a execução orçamentária do exercício, não poderá haver a realização de despesas ou a assunção de obrigações que extrapolem os limites estabelecidos na lei de diretrizes orçamentárias, exceto se previamente autorizadas, mediante a abertura de créditos suplementares ou especiais. (Incluído pela Emenda Constitucional no 45, de 2004)".

7 "Art. 95. Os juízes gozam das seguintes garantias: I - vitaliciedade, que, no primeiro grau, só será adquirida após dois anos de exercício, dependendo a perda do cargo, nesse período, de deliberação do tribunal a que o juiz estiver vinculado, e, nos demais casos, de sentença judicial transitada em julgado; II - inamovibilidade, salvo por motivo de interesse público, na forma do art. 93, VIII; III - irredutibilidade de subsídio, ressalvado o disposto nos arts. 37, X e XI, 39, §40, 150, II, 153, III, e 153, § $2^{\circ}$, I. (Redação dada pela Emenda Constitucional no 19, de 1998)".

8 "§ 10 O Ministério Público da União tem por chefe o Procurador-Geral da República, nomeado pelo Presidente da República dentre integrantes da carreira, maiores de trinta e cinco anos, após a aprovação de seu nome pela maioria absoluta dos membros do Senado Federal, para mandato de dois anos, permitida a recondução. (...) § $3^{\circ}$ Os Ministérios Públicos dos Estados e o do Distrito Federal e Territórios formarão lista tríplice dentre integrantes da carreira, na forma da lei respectiva, para escolha de seu Procurador-Geral, que será nomeado pelo Chefe do Poder Executivo, para mandato de dois anos, permitida uma recondução". 
LIMAS TOMIO, Fabrício Ricardo de; ROBL FILHO, Ilton Norberto. Autonomia e prerrogativas do ministério público brasileiro em perspectiva comparada: construindo um índice de independência/autonomia. Revista Eletrônica Direito e Política, Programa de Pós-Graduação Stricto Sensu em Ciência Jurídica da UNIVALI, Itajaí, v.16, n.3, 30 quadrimestre de 2021. Disponível em: www.univali.br/direitoepolitica - ISSN 1980-7791.

competência e o funcionamento dos respectivos órgãos jurisdicionais e administrativo", segundo o artigo 96, I, CF/88.

Ainda, como a estruturação semelhante do Ministério Público e do Judiciário não é um arranjo constitucional comum à imensa maioria dos 190 Estados nacionais comparados pelo $\mathrm{CCP}$, a construção de um índice comparativo próprio de autonomia/independência do MP (Prosecutorial Independence, PI, de jure) torna-se uma tarefa necessária na compreensão do grau de autonomia do Ministério Público brasileiro.

As garantias e as prerrogativas do judiciário estão mais presentes na constituição da maior parte dos países. A consulta ao texto das constituições na base de dados do CCP demonstra que: de 190 Estados nacionais, 178 constituições (dados atualizados para 2020) fazem menção explícita à noção de Judicial Independence e todas as constituições possuem o termo structure of the courts em seu texto. Por outro lado, 161 constituições relatam a presença do termo Public Prosecutor [prosecutor, prosecutor general, attorney general ou termo semelhante], sem, necessariamente, atribuir garantias de independência e autonomia ao mais alto representante do Ministério Público de cada país e menos ainda ao conjunto dos representantes do Ministério Público. Dessa forma, até preliminarmente, antes da análise dos dados, é possível definir, comparativamente, a Independência do Ministério Público brasileiro como superior à Independência do Judiciário, quando contrastado com as garantidas constitucionais promovidas por outros países.

Em relação aos dados do CCP para comparar os poderes constitucionalizados (governo, legislaturas e tribunais nacionais), há Poder Atribuído Executivo (Executive Power, CCP), o qual é composto por sete indicadores de poder fixados ao governo nacional, isto é, (1) poder de iniciar o processo legislativo; (2) poder de emitir decretos; (3) poder de propor emendas constitucionais; (4) poder de decretar estado de emergência; (5) poder de veto; (6) poder de impugnar judicialmente a constitucionalidade da legislação; e (7) poder de dissolver as legislaturas. O Executivo brasileiro possui cinco desses atributos na Constituição Federal de 1988. Dessa 
LIMAS TOMIO, Fabrício Ricardo de; ROBL FILHO, Ilton Norberto. Autonomia e prerrogativas do ministério público brasileiro em perspectiva comparada: construindo um índice de independência/autonomia. Revista Eletrônica Direito e Política, Programa de Pós-Graduação Stricto Sensu em Ciência Jurídica da UNIVALI, Itajaí, v.16, n.3, 30 quadrimestre de 2021. Disponível em: www.univali.br/direitoepolitica - ISSN 1980-7791.

maneira, o Executivo Nacional/Federal brasileiro é superior à maioria dos Estados nacionais, já que mais da metade das constituições concede ao Executivo nacional quatro ou menos poderes relacionados a essas competências (ver Gráfico 1).

Sobre o item (4), no estado de sítio, o Presidente no Brasil deve obter a autorização do Congresso Nacional para sua decretação, após sólido relato dos motivos determinantes pelo Chefe de Estado e de Governo, de acordo com o artigo 137, $\mathrm{CF} / 88^{9}$. Dessa maneira, considera-se que a Presidência não tem o poder de decretar estado de emergência. Ainda, o Executivo Nacional/Federal não detém o poder de dissolver as legislaturas, que é o item (7) do índice. Ou seja, comparativa e constitucionalmente, a competência do Executivo brasileiro pode ser classificada como um pouco acima da média dos indicadores encontrados nos Estados nacionais.

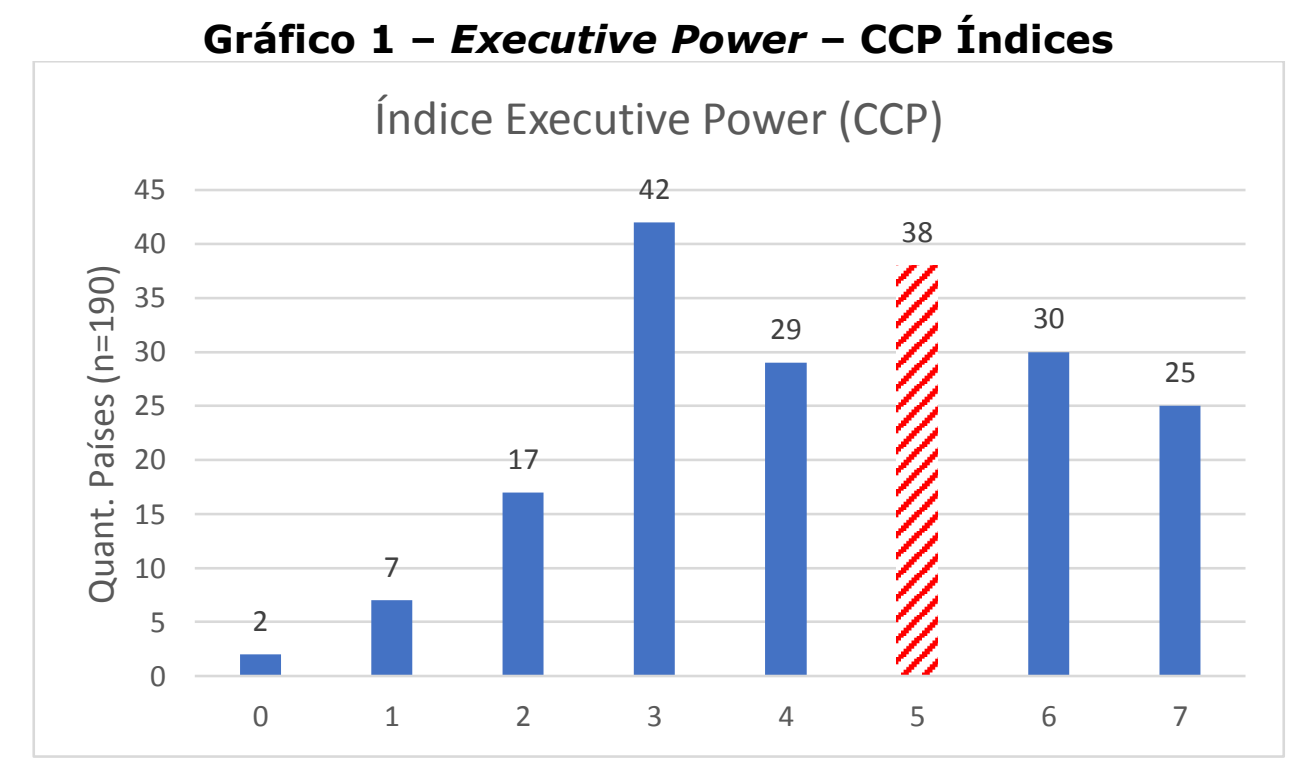

Fonte: DIRPOL/PPGD/UFPR com os dados do CCP Índices ${ }^{10}$

9 "Art. 137. O Presidente da República pode, ouvidos o Conselho da República e o Conselho de Defesa Nacional, solicitar ao Congresso Nacional autorização para decretar o estado de sítio nos casos de: I comoção grave de repercussão nacional ou ocorrência de fatos que comprovem a ineficácia de medida tomada durante o estado de defesa; II - declaração de estado de guerra ou resposta a agressão armada estrangeira. Parágrafo único. O Presidente da República, ao solicitar autorização para decretar o estado de sítio ou sua prorrogação, relatará os motivos determinantes do pedido, devendo o Congresso Nacional decidir por maioria absoluta".

10 Organizado pelos pesquisadores do DIRPOL/PPGD/UFPR com os dados do CCP Índices, https://comparativeconstitutionsproject.org/ccp-rankings/. No destaque, classe com a posição conferida pela CF/88. 
LIMAS TOMIO, Fabrício Ricardo de; ROBL FILHO, Ilton Norberto. Autonomia e prerrogativas do ministério público brasileiro em perspectiva comparada: construindo um índice de independência/autonomia. Revista Eletrônica Direito e Política, Programa de Pós-Graduação Stricto Sensu em Ciência Jurídica da UNIVALI, Itajaí, v.16, n.3, $3^{\circ}$ quadrimestre de 2021. Disponível em: www.univali.br/direitoepolitica - ISSN 1980-7791.

Por outro lado, o Legislative Power, no Brasil, coloca o Congresso Nacional dentre os $6 \%$ dos países que, comparativamente, mais atribuem poder à legislatura nacional pela constituição (ver Gráfico 2). Dos 190 países, apenas sete possuem o mesmo índice brasileiro e somente cinco nações detêm maiores valores do índice em relação ao Brasil. O índice brasileiro é de 0.48, sendo um índice que pode variar entre 0,0 e 1,0. Essa pontuação resulta da média de 32 indicadores binários, representando os números maiores um conjunto mais robusto de poderes ao Legislativo. O maior valor do índice (0.62) é atribuído apenas a um país: o Haiti. O segundo índice mais elevado de poder/competência do Legislativo $(0,52)$ é encontrado em quatro países: Bulgária, Camboja, Eslováquia e Suécia. O terceiro índice $(0,48)$, além do Brasil, é compartilhado com outros seis Estados nacionais: Egito, Eritréia, Etiópia, Finlândia, Ucrânia e Uruguai.

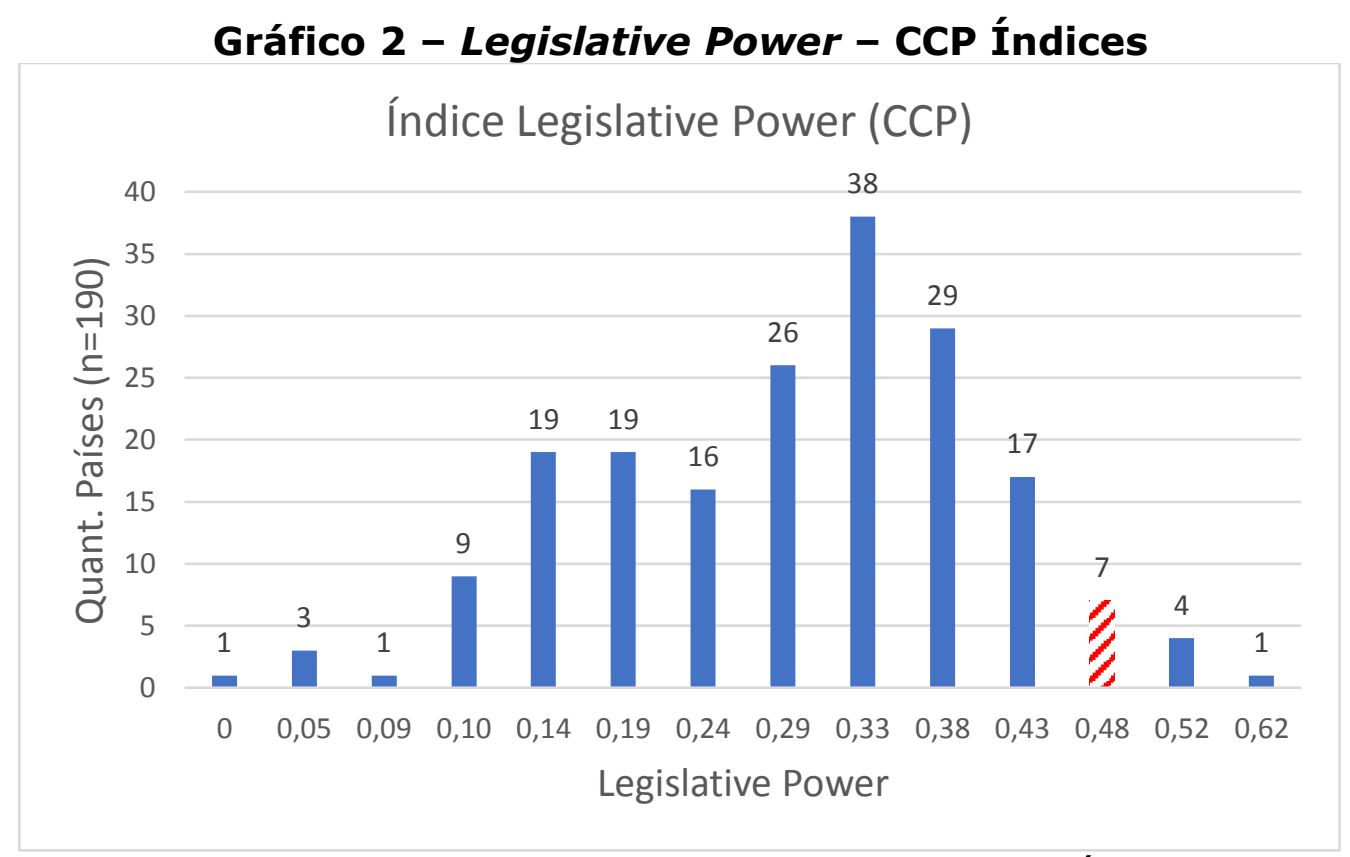

Fonte: DIRPOL/PPGD/UFPR com os dados do CCP Índices ${ }^{11}$

11 Organizado pelos pesquisadores do DIRPOL/PPGD/UFPR com os dados do CCP Índices, https://comparativeconstitutionsproject.org/ccp-rankings/. No destaque, classe com a posição conferida pela CF/88. 
LIMAS TOMIO, Fabrício Ricardo de; ROBL FILHO, Ilton Norberto. Autonomia e prerrogativas do ministério público brasileiro em perspectiva comparada: construindo um índice de independência/autonomia. Revista Eletrônica Direito e Política, Programa de Pós-Graduação Stricto Sensu em Ciência Jurídica da UNIVALI, Itajaí, v.16, n.3, 30 quadrimestre de 2021. Disponível em: www.univali.br/direitoepolitica - ISSN 1980-7791.

Da mesma forma, a constitucionalização da Judicial Independence, no Brasil, encontra-se no primeiro decil de atribuição de garantias aos tribunais nacionais (superiores), ou seja, a independência judicial brasileira possui índice dentre os 10\% de países com índices mais elevados do conjunto de 190 nações comparadas (ver Gráfico 3). As seis garantias constitucionais do indicador mensurados pelo CCP são as seguintes: (1) constituição contém uma declaração explícita de independência judicial, (2) constituição prevê que os juízes tenham nomeações vitalícias; (3) nomeações para o tribunal mais alto envolvem um conselho judicial ou dois (ou mais) atores (poderes), (4) a remoção é proibida ou limitada, ou requer uma proposta com voto de maioria qualificada na legislatura, ou apenas um conselho judicial pode propor a remoção e outro ator político é obrigado a aprovar tal proposta; (5) a remoção se limita explicitamente a crimes e outras questões de má conduta, traição ou violações da constituição e (6) os salários judiciais são protegidos de redução (irredutibilidade). Frisa-se que, segundo nossa compreensão, a equipe do CCP classificou erroneamente o Brasil, porque as seis garantias constitucionais do indicador estão presentes na $\mathrm{CF} / 88$. As bases de dados desagregados do CCP indicam que o Brasil não teria previsão constitucional no item (4) - a remoção é proibida ou limitada, ou requer uma proposta com voto de maioria qualificada na legislatura, ou apenas um conselho judicial pode propor a remoção e outro ator político é obrigado a aprovar tal proposta. Entretanto, por questão de coerência, o índice atribuído pelo CCP será mantido nas comparações realizadas no presente artigo. 
LIMAS TOMIO, Fabrício Ricardo de; ROBL FILHO, Ilton Norberto. Autonomia e prerrogativas do ministério público brasileiro em perspectiva comparada: construindo um índice de independência/autonomia. Revista Eletrônica Direito e Política, Programa de Pós-Graduação Stricto Sensu em Ciência Jurídica da UNIVALI, Itajaí, v.16, n.3, 30 quadrimestre de 2021. Disponível em: www.univali.br/direitoepolitica - ISSN 1980-7791.

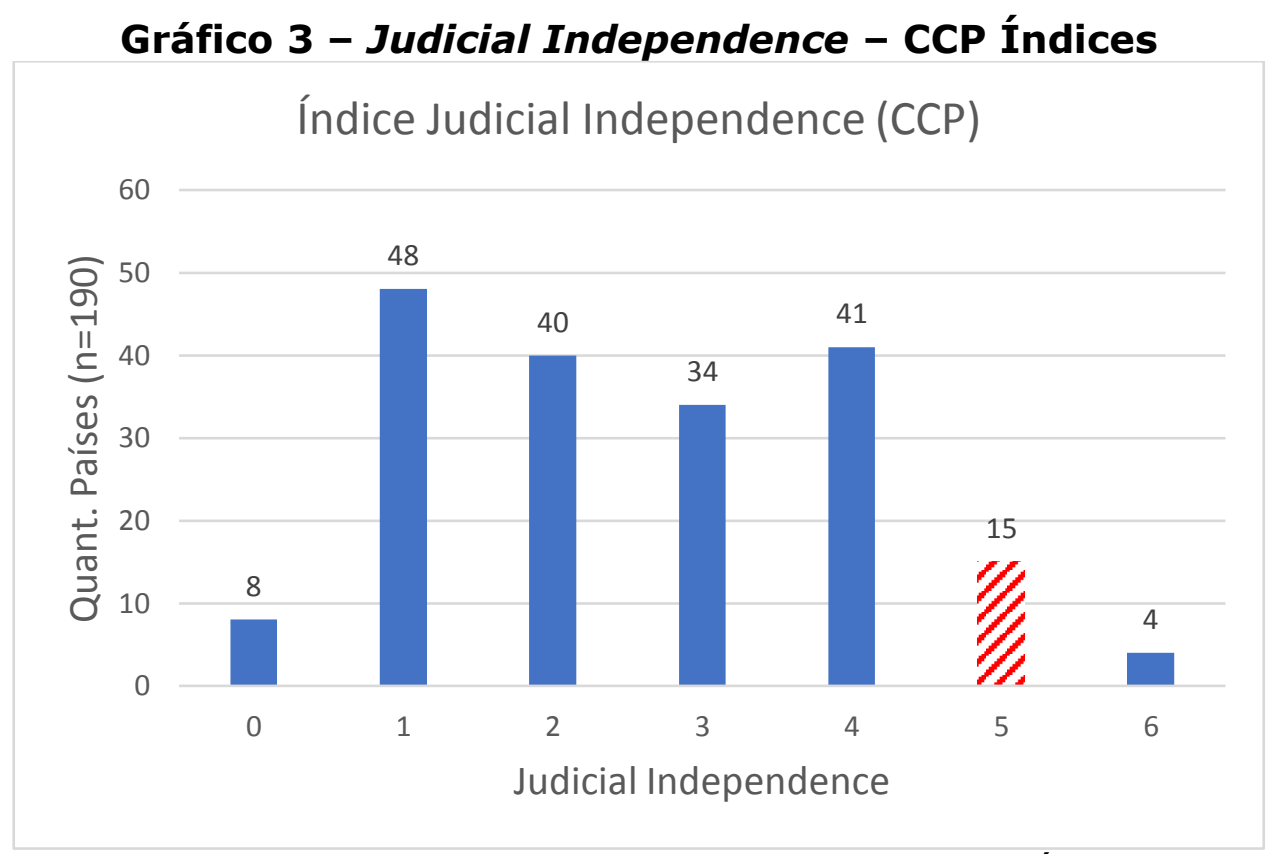

Fonte: DIRPOL/PPGD/UFPR com os dados do CCP Índices ${ }^{12}$

Na definição dada pelo CCP para independência judicial, das seis características institucionais (prerrogativas constitucionalizadas) que favorecem a independência e a autonomia judiciais, a CF/88 estabelece cinco ao Poder Judiciário do Brasil. É o segundo maior índice, compartilhado pelo Brasil e outros 14 países: Albânia, Bangladesh, Butão, Quênia, Kosovo, Maldivas, Ilhas Marshall, Peru, Serra Leoa, Eslováquia, Eslovênia, África do Sul, Essautíni-Suazilândia e Uganda. Segundo o índice do CCP, somente quatro países possuem as seis características de independência constitucionalizadas: Argentina, Bulgária, Gambia, Nepal.

Em síntese e na perspectiva comparada, a constituição brasileira a) garante maior independência/autonomia ao Judiciário do que poderes à legislatura nacional, mas b) a independência e a autonomia judiciais e os poderes/competências do Legislativo são mais robustos do que os poderes atribuídos ao Executivo. Como foi descrito antes,

12 Organizado pelos pesquisadores do DIRPOL/PPGD/UFPR com os dados do CCP Índices, https://comparativeconstitutionsproject.org/ccp-rankings/. No destaque, classe com a posição conferida pela $\mathrm{CF} / 88$. 
LIMAS TOMIO, Fabrício Ricardo de; ROBL FILHO, Ilton Norberto. Autonomia e prerrogativas do ministério público brasileiro em perspectiva comparada: construindo um índice de independência/autonomia. Revista Eletrônica Direito e Política, Programa de Pós-Graduação Stricto Sensu em Ciência Jurídica da UNIVALI, Itajaí, v.16, n.3, $3^{\circ}$ quadrimestre de 2021. Disponível em: www.univali.br/direitoepolitica - ISSN 1980-7791.

a maioria esmagadora das garantias do judiciário é estendida constitucionalmente ao Ministério Público.

\section{Relações dos Índices Comparativos de Independência do Judiciário e das Competências e dos Poderes do Executivo e do Legislativo a Partir Especialmente do Comparative Constitutions Project - CCP}

Os dados do CCP não permitem fazer uma correlação (estatística) ou estabelecer uma causalidade entre a constitucionalização das características das instituições (poderes). Em outras palavras, no constitutional making, a constitucionalização de prerrogativas e das competências não é um jogo de soma zero, ainda que a relação entre poderes, órgãos constitucionais autônomos e instituições estatais decorrentes possa ser investigada por uma abordagem de teoria dos jogos. Dessa forma, a maior ou a menor independência judicial constitucionalizada, no Estado nacional (que, conforme já descrito, no Brasil, é um proxy da independência do Ministério Público) não está fortemente associada, na perspectiva descritiva sobre esse fenômeno, à maior ou à menor atribuição de poderes/competências ao Executivo ou à legislatura nacional de um mesmo país. ${ }^{13}$

13 O resultado da correlação linear $r$ (Pearson) e regressão linear $\left(R^{2}\right)$ entre o índice de judicial Independence e os índices de poder legislativo e poder executivo são os seguintes: com legislative power $\left(r=0,1274 ; R^{2}=0,0162\right)$; executive power $\left(r=-0,1840 ; R^{2}=0,0338\right)$. A associação entre judicial independence e executive/legislative power é muito fraca ( $\mathrm{R}^{2}$ próximo a zero). O maior poder legislativo constitucionalizado em um país está levemente associado a maior independência judicial na constituição. A relação é inversa (negativa) da independência judicial com a constitucionalização de poderes legislativos ao poder executivo de um país. 
LIMAS TOMIO, Fabrício Ricardo de; ROBL FILHO, Ilton Norberto. Autonomia e prerrogativas do ministério público brasileiro em perspectiva comparada: construindo um índice de independência/autonomia. Revista Eletrônica Direito e Política, Programa de Pós-Graduação Stricto Sensu em Ciência Jurídica da UNIVALI, Itajaí, v.16, n.3, $3^{\circ}$ quadrimestre de 2021. Disponível em: www.univali.br/direitoepolitica - ISSN 1980-7791.

\section{Gráfico 4 - Judicial Independence (média) X Executive/Legislative Power (classes) - CCP Indices}

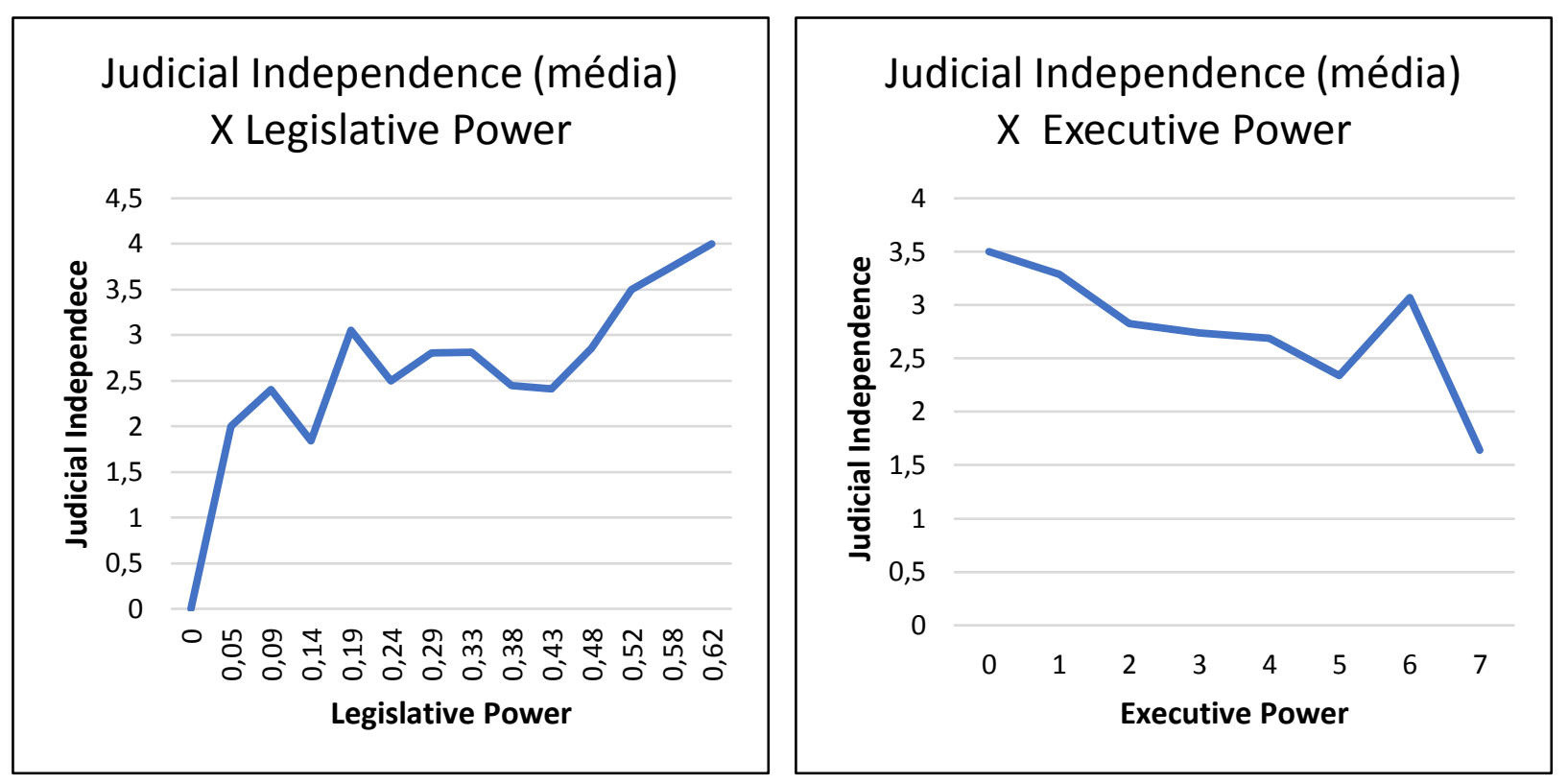

Fonte: DIRPOL/PPGD/UFPR com os dados do CCP Índices ${ }^{14}$

Na perspectiva descritiva do fenômeno, apenas se observa uma leve tendência de constitucionalização maior da Judicial Independence com a constitucionalização de maior Legislative Power e de menor Executive Power. Ou seja, um conjunto de poderes e competências maiores ao legislativo, na constituição, é frequentemente acompanhado de uma maior independência judicial, assim como as competências mais robustas do poder executivo relacionam-se, frequentemente, com a menor independência judicial (ver Gráfico 4).

Ainda, é possível perceber que: (1) não há uma associação clara entre a constitucionalização de poderes e a independência judicial e, (2) no Brasil, Judiciário, Legislativo e Executivo são dotados de índices (medidos pelos indicadores do CCP) semelhantes na constituição, ao contrário dos demais países (exceção ao México) (ver Gráfico 5). Por outro lado, Chile, França, Portugal e Espanha constitucionalizam mais

14 Organizado pelos pesquisadores do DIRPOL/PPGD/UFPR com os dados do CCP Índices, https://comparativeconstitutionsproject.org/ccp-rankings/. 
LIMAS TOMIO, Fabrício Ricardo de; ROBL FILHO, Ilton Norberto. Autonomia e prerrogativas do ministério público brasileiro em perspectiva comparada: construindo um índice de independência/autonomia. Revista Eletrônica Direito e Política, Programa de Pós-Graduação Stricto Sensu em Ciência Jurídica da UNIVALI, Itajaí, v.16, n.3, 30 quadrimestre de 2021. Disponível em: www.univali.br/direitoepolitica - ISSN 1980-7791.

poderes ao executivo em comparação com as competências do legislativo e com o nível e a intensidade da independência do Judiciário. A Argentina fixa substanciais autonomia e independência ao Judiciário, mas estabelece constitucionalmente um menor conjunto de competências aos demais poderes estatais.

O Brasil e o México, nas suas constituições nacionais, distribuíram mais equilibradamente as competências e as garantias mensuradas aos três poderes. Nesses países, os índices do Executivo, Judiciário e Legislativo são mais próximos, porém em ambos o judiciário é o mais fortemente amparado em prerrogativas e garantias constitucionais (descritas nos índices produzidos pelo CCP).

\section{Gráfico 5 - Judicial Independence X Executive Power X Legislative Power - amostra CCP}

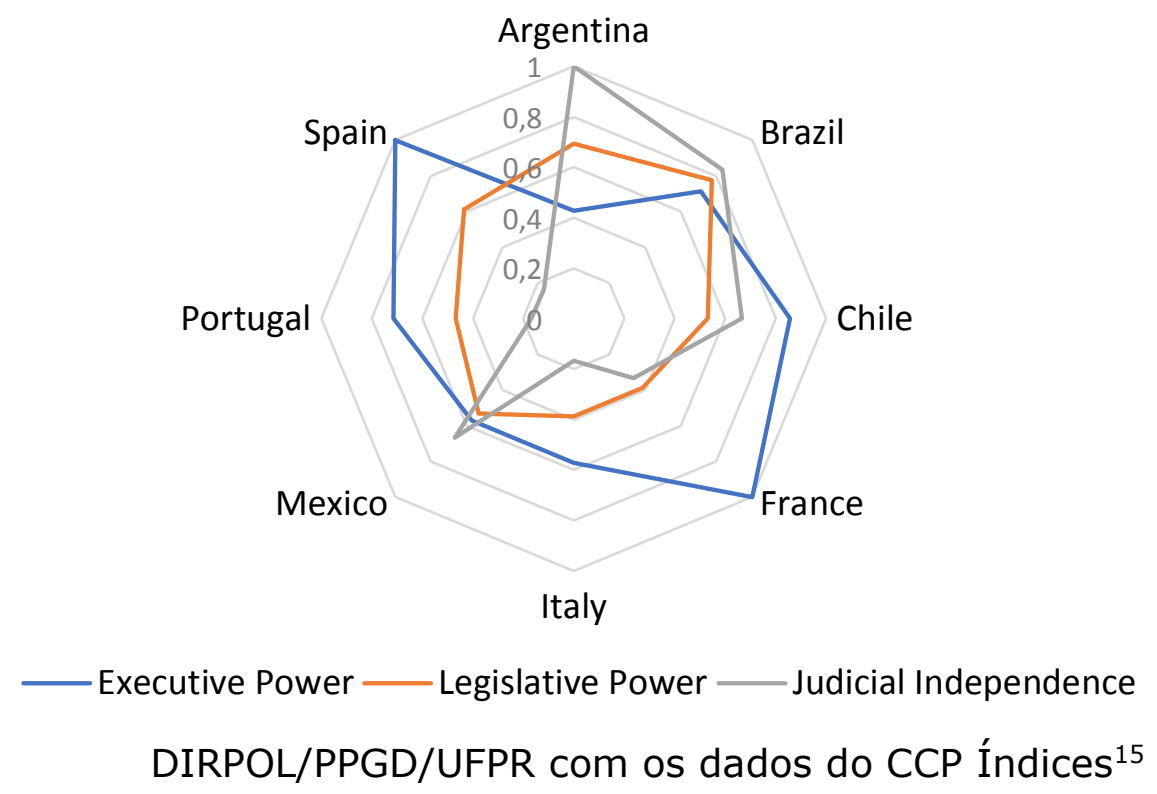

Feitas essas considerações sobre os índices e suas relações no Executivo, Legislativo e Judiciário, a próxima seção ingressa no objeto central do texto, o qual trata do índice de independência/autonomia do Ministério Público, além da sua associação e

15 Organizado pelos pesquisadores do DIRPOL/PPGD/UFPR com os dados do CCP Índices, https://comparativeconstitutionsproject.org/ccp-rankings/. 
LIMAS TOMIO, Fabrício Ricardo de; ROBL FILHO, Ilton Norberto. Autonomia e prerrogativas do ministério público brasileiro em perspectiva comparada: construindo um índice de independência/autonomia. Revista Eletrônica Direito e Política, Programa de Pós-Graduação Stricto Sensu em Ciência Jurídica da UNIVALI, Itajaí, v.16, n.3, 30 quadrimestre de 2021. Disponível em: www.univali.br/direitoepolitica - ISSN 1980-7791.

eventualmente da causalidade com as prerrogativas e as competências de outras instituições, órgãos e poderes estatais.

\section{3. Índice de Independência (Autonomia, de Jure) do Ministério Público}

Com a promulgação da Constituição Federal de 1988, o Ministério Público passou a gozar de efetiva autonomia institucional (Título IV - Da Organização dos Poderes Capítulo IV - Das Funções Essenciais à Justiça, Seção I - Ministério Público), com independência funcional e autonomias administrativa e financeira. Alexandre de Moraes assevera que a instituição é "independente no exercício de suas funções, não ficando sujeito às ordens de quem quer que seja, somente devendo prestar contas de seus atos à Constituição, às leis e à sua consciência"16. Por sua vez, Mazzilli ${ }^{17}$ entende que "não se admite possam Ministério Público e seus agentes fazer simplesmente o que bem quiserem, sem dar contas à lei e a ninguém".

Carvalho e Leitão $^{18}$ abordam o novo desenho institucional do Ministério Público, comentando que, embora essa instituição já tenha adquirido diversas prerrogativas anteriormente, somente com a atual constituição CF/88 foi estabelecido um papel relevante e autônomo politicamente no âmbito nacional. Ainda, Sadek ${ }^{19}$ afirma que o

${ }^{16}$ MORAES, Alexandre. Direito Constitucional. 13 ed. São Paulo: Atlas, 2003. p. 402.

17 MAZZILLI, Hugo Nigro. A independência do Ministério Público. Palestra proferida na Associação do Ministério Público do Rio de Janeiro em 11.03.1996. transcrita em Juris Síntese Millennium [Cd-rom]: Síntese, jan 2001). Disponível em: http://www.mazzilli.com.br/pages/artigos/indmp.pdf. Acesso em 11.10.2021. P. 07.

${ }^{18}$ CARvalho, Ernani; LeitaO, Natalia. O Novo desenho institucional do Ministério Publico e o Processo de Judicialização da Política [online]. 2010. Disponível em: http://www.scielo.br/pdf/rdgv/v6n2/a03v6n2.pdf. Acesso em 03.11.2021.

${ }^{19}$ SADEK, Maria Tereza. A Construção de um novo Ministério Público resolutivo. De jure: Revista Jurídica do Ministério Público do Estado de Minas Gerais, Belo Horizonte, n. 12, p. 130-139, 2009. 
LIMAS TOMIO, Fabrício Ricardo de; ROBL FILHO, Ilton Norberto. Autonomia e prerrogativas do ministério público brasileiro em perspectiva comparada: construindo um índice de independência/autonomia. Revista Eletrônica Direito e Política, Programa de Pós-Graduação Stricto Sensu em Ciência Jurídica da UNIVALI, Itajaí, v.16, n.3, 30 quadrimestre de 2021. Disponível em: www.univali.br/direitoepolitica - ISSN 1980-7791.

Ministério Público no Brasil, diferentemente dos demais ao redor do mundo, apresenta um perfil institucional próprio, robusto e autônomo:

Gostaria de iniciar o desenvolvimento dessa tese com algumas comparações. Em primeiro lugar, se considerarmos o panorama internacional, perceberemos que o Ministério Público brasileiro é singular. Eu costumo brincar dizendo que, quando as pessoas se gabam exclamando que a jabuticaba só existe no Brasil, retruco, observando que o que existe de fato só no Brasil é o nosso Ministério Público. Podemos encontrar instituições análogas na América Latina, no mundo Europeu e na América do Norte. Em nenhum dos países, contudo, vamos nos deparar com um Ministério Público que apresente um perfil institucional semelhante ou que ostente igual conjunto de atribuições. O nosso Ministério Público, a partir da Constituição de 1988, passou a ser uma instituição que tem pouca semelhança com seus congêneres no exterior e tampouco com o Ministério Público brasileiro do passado. Eu até diria, ousando uma observação ainda mais radical, que o nome é o mesmo, mas a instituição não. Várias características mudaram. Entre essas alterações, ressalte-se, desde logo, a sua localização institucional e o rol de suas atribuições (grifos nossos). ${ }^{20}$

Sadek $^{21}$ relata que o Ministério Público do Brasil, em relação aos demais países da América Latina, é muito distinto. Por exemplo, na Costa Rica, Colômbia e Paraguai, o Ministério Público é dependente do Judiciário e, no México, República Dominicana e Uruguai, relaciona-se com o Executivo.

Em análise comparada, grande parte da literatura sobre a autonomia e independência do Ministério Público descreve de forma estanque as características do Executivo, do Legislativo e do Judiciário, assim como do Ministério Público, em seu país, sem estabelecer indicadores que permitam mensurar diferentes graus de competências, prerrogativas, independência e autonomia. Dentre a literatura, o estudo comparativo

\footnotetext{
${ }^{20}$ SADEK, Maria Tereza. A Construção de um novo Ministério Público resolutivo. De jure: Revista Jurídica do Ministério Público do Estado de Minas Gerais, Belo Horizonte, n. 12, p. 130-139, 2009. p. 130.

${ }^{21}$ SADEK, Maria Tereza. A Construção de um novo Ministério Público resolutivo. De jure: Revista Jurídica do Ministério Público do Estado de Minas Gerais, Belo Horizonte, n. 12, p. 130-139, 2009. p. 131.
} 
LIMAS TOMIO, Fabrício Ricardo de; ROBL FILHO, Ilton Norberto. Autonomia e prerrogativas do ministério público brasileiro em perspectiva comparada: construindo um índice de independência/autonomia. Revista Eletrônica Direito e Política, Programa de Pós-Graduação Stricto Sensu em Ciência Jurídica da UNIVALI, Itajaí, v.16, n.3, 30 quadrimestre de 2021. Disponível em: www.univali.br/direitoepolitica - ISSN 1980-7791.

feito por Dias e Azevedo 22 analisa algumas diferenças entre o Ministério Público em Portugal, Espanha, França, Itália, Brasil e Argentina.

Na literatura, é possível encontrar tentativas de produzir, independentemente da mensuração de poderes e garantias de outras instituições e poderes, índices de independência/autonomia do Ministério Público (Prosecutorial Independence-PI). Um indicador abrangente (para 78 países) foi construído por Van Aaken, Feld e Voigt ${ }^{23}$ para mensurar a independência formal (de jure PI) e a independência de facto. ${ }^{24}$

Para classificar o grau de independência formal do MP (de jure PI) em um indicador, são sumarizadas 21 variáveis institucionais. Por sua vez, o indicador de independência factual (de facto PI) é composto por sete variáveis retiradas de surveys sobre a percepção da independência do MP entre especialistas ${ }^{25}$. Dessa forma, o objetivo dos autores é relacionar a Prosecutorial Independence (formal e factual) com o combate à corrupção (ou a percepção do combate à corrupção obtida por surveys com especialistas e com a população). A conclusão associou positivamente de facto PI e negativamente de jure PI com a percepção de menores índices de corrupção ${ }^{26}$,

22 DIAS, Paulo J.; AZEVEDO, Rodrigo G. de. O papel do Ministério Público: estudos comparados dos países latino-americanos. São Paulo: Almedina, 2008.

23 VAN AAKEN, Anne; FELD, Lars P.; VOIGT, Stefan. Do independent prosecutors deter political corruption? An empirical evaluation across seventy-eight countries. American Law and Economics Review, v. 12, n. 1, p. 204-244, 2010.

${ }^{24}$ Os indicadores de independência formal do MP de Van Aaken, Feld e Voigt (2010) são detalhados e minuciosamente revistos por Carvalho e Leitão (2019, p. 87 e seg.), com conclusões sobre a importância de desagregar indicadores internos e externos de independência formal para o estudo do caso brasileiro. Apesar de interessantes as conclusões de Carvalho e Leitão (2019, p. 108), não é possível incorporar algumas de suas sugestões de mensuração de independência do MP neste artigo, devido à indisponibilidade de informações legais e constitucionais dos outros países comparados.

25 VAN AAKEN, Anne; FELD, Lars P.; VOIGT, Stefan. Do independent prosecutors deter political corruption? An empirical evaluation across seventy-eight countries. American Law and Economics Review, v. 12, n. 1, p. 204-244, 2010. p. 213-218.

${ }^{26}$ De acordo com Van Aaken, Feld e Voigt (2010, p. 205): "The indicators for de jure and de facto PI are available for seventy-eight and seventy-six countries, respectively. De facto PI turns out to be highly and robustly significant for explaining variation in perceived corruption: the more independent the prosecutors factually are, the lower the expected level of corruption, c.p. De jure PI has an unexpected sign: more independence is correlated with more corruption. But this variable never reaches conventional levels of significance". 
LIMAS TOMIO, Fabrício Ricardo de; ROBL FILHO, Ilton Norberto. Autonomia e prerrogativas do ministério público brasileiro em perspectiva comparada: construindo um índice de independência/autonomia. Revista Eletrônica Direito e Política, Programa de Pós-Graduação Stricto Sensu em Ciência Jurídica da UNIVALI, Itajaí, v.16, n.3, 30 quadrimestre de 2021. Disponível em: www.univali.br/direitoepolitica - ISSN 1980-7791.

existindo a percepção social de que a corrupção é menor nos países com alto índice de PI de facto. Nos países com um robusto índice PI de jure, observa-se uma percepção mais elevada acerca da corrupção.

Apesar de relevante, entendemos que esses índices teriam pouca utilidade para os objetivos do presente estudo, pois não é possível replicar claramente os indicadores institucionais para mensurar a independência e a autonomia do MP e, sobretudo, porque o combate à corrupção como efeito da Prosecutorial Independence (logo, a seleção dos indicadores de jure e de facto associados a esse efeito) não é o foco de deste texto e desta investigação. Além disso, a informação de independência do MP extraída dos surveys (de facto) e direcionada à percepção do combate à corrupção restringe a possibilidade de mensurar a liberdade de atuação do MP em outras áreas, inclusive em outras questões da esfera política e na execução das políticas públicas. Por fim, Van Aaken, Feld e Voigt $^{27}$ verificam que os dois indicadores não possuem uma correlação positiva (de facto PI e de jure PI): a presença de mais garantias institucionais (constitucionais e legais) do MP em um país não se relaciona com a maior percepção de especialistas e da população sobre a independência do MP.

Outro índice de Prosecutorial Independence (de facto PI) presente na literatura é o proposto por Gutmann e Voigt ${ }^{28}$, sendo construídos indicadores também com base em surveys como do World Justice Project - annual rule of law index, o qual é composto por oito categorias como ausência de corrupção e justiça criminal. Da mesma forma, o índice de facto desses autores tem objetivos que distanciam da possibilidade de sua utilização neste texto ${ }^{29}$.

27 VAN AAKEN, Anne; FELD, Lars P.; VOIGT, Stefan. Do independent prosecutors deter political corruption? An empirical evaluation across seventy-eight countries. American Law and Economics Review, v. 12, n. 1, p. 204-244, 2010. p. 220.

${ }^{28}$ GUTMANNN, Jerg; VOIGT, Stefan: The Independence of Prosecutors and Government Accountability. ILE Working Paper Series, No. 8, University of Hamburg, Institute of Law and Economics (ILE), Hamburg, 2017. p. 4.

${ }^{29}$ Isto fica claro observando como os autores descrevem o indicador, que foi obtido a partir de dados de 99 países: "The two measures proposed here make [prosecutorial independence] and PA [prosecutorial 
LIMAS TOMIO, Fabrício Ricardo de; ROBL FILHO, Ilton Norberto. Autonomia e prerrogativas do ministério público brasileiro em perspectiva comparada: construindo um índice de independência/autonomia. Revista Eletrônica Direito e Política, Programa de Pós-Graduação Stricto Sensu em Ciência Jurídica da UNIVALI, Itajaí, v.16, n.3, 30 quadrimestre de 2021. Disponível em: www.univali.br/direitoepolitica - ISSN 1980-7791.

Dos 78 países analisados por Gutmann e Voigt ${ }^{30}$, apenas 14 possuem indicadores de independência formal do MP (PI, de jure) maiores do que os do Brasil. Como descreveremos em seguida, apesar de a mensuração da autonomia e da independência institucional do MP que desenvolveremos neste artigo ser distinta (no cálculo, na quantidade de países e na abrangência de indicadores institucionais) do índice de Prosecutorial Independence (de jure PI) proposto por Gutmann e Voigt ${ }^{31}$, há uma relativa convergência na atribuição de independência formal comparada do MP no Brasil: o texto de Gutmann e Voigt e o nosso demonstram a elevada independência do Ministério Público no Brasil.

Como já informado, o que pretendemos é desenvolver um índice de Independência/Autonomia do MP com base em prerrogativas institucionais (de jure), dado que a percepção de independência do MP (de facto) extraída de surveys com especialistas ou com a população em geral não seria satisfatório para o nosso objetivo. A maior dificuldade metodológica é o levantamento e a compilação da legislação infraconstitucional de cada país. Nesse sentido, a base de dados mais completa e abrangente, além de ter como fonte uma instituição pública relevante, sobre garantias e prerrogativas institucionais (constituição e legislação) atribuída ao Ministério Público (ou congêneres), é organizada pelo CEPEJ (The European

accountability] comparable across countries. Each measure is based on one specific question in the WJP's general population survey. The questions aim at identifying to what extent the "lack of independence of prosecutors" or the "corruption of prosecutors" constitute a problem for the criminal investigation system in the city in which the respondent lives. To indicate the significance of the problem, the respondent can choose an integer value between 1 and 10 from a scale. The WJP then aggregates all responses at the country level, such that 0 indicates the absence of PI or a very high level of PA, whereas 1 indicates a very high level of PI or the absence of PA. In other words, higher values on WJP-indicators reflect a better quality of governance. All indicator values for 99 countries are documented in Appendix A" (GUTMANN e VOIGT, 2017, p. 4).

30 GUTMANNN, Jerg; VOIGT, Stefan: The Independence of Prosecutors and Government Accountability. ILE Working Paper Series, No. 8, University of Hamburg, Institute of Law and Economics (ILE), Hamburg, 2017.

31 GUTMANNN, Jerg; VOIGT, Stefan: The Independence of Prosecutors and Government Accountability. ILE Working Paper Series, No. 8, University of Hamburg, Institute of Law and Economics (ILE), Hamburg, 2017. 
LIMAS TOMIO, Fabrício Ricardo de; ROBL FILHO, Ilton Norberto. Autonomia e prerrogativas do ministério público brasileiro em perspectiva comparada: construindo um índice de independência/autonomia. Revista Eletrônica Direito e Política, Programa de Pós-Graduação Stricto Sensu em Ciência Jurídica da UNIVALI, Itajaí, v.16, n.3, 30 quadrimestre de 2021. Disponível em: www.univali.br/direitoepolitica - ISSN 1980-7791.

Commission for the Efficiency of Justice), órgão oficial da Comunidade Europeia ${ }^{32}$. Partiremos desses dados descritivos para construir a nossa amostra e o índice de autonomia/independência do MP que chamaremos de: ÍNDICE de Autonomia MP (CEPEJ/DIRPOL). Essa escolha metodológica limita, neste momento, a comparação do Brasil com países europeus, o que pretendemos complementar no futuro pela compilação de dados institucionais de uma amostra ampliada com países da América Latina.

Com base nos dados descritivos do CEPEJ 33 para 47 países europeus, construímos um índice de autonomia/independência do MP [CEPEJ/DIRPOL] que varia de 0-1 (conforme o descrito no Quadro A1 e Tabela A1, no Anexo), contendo os seguintes indicadores: (1) independência institucional, jurídica e legal do Ministério Público; (2) regulamento para evitar instruções específicas para processar ou não, dirigido a um procurador em um tribunal; (3) vitaliciedade/estabilidade dos membros do Ministério Público e; (4) o papel do Ministério Público (em 14 itens distintos de sua atuação funcional). Aos dados dos países europeus, extraídos diretamente dos relatórios e das bases de dados do CEPEJ, foram acrescidas as características institucionais (previstas em lei e na constituição) específicas e relativas ao Brasil para realizar a comparação. O CEPEJ verifica, através dos itens (1) e (2) do nosso índice, as autonomias institucional, administrativa, jurídica e legal do Ministério Público, isto é, se órgão e seus membros são legalmente independentes e se estão subordinados ao Ministério da Justiça ou a outra autoridade centralizada. O princípio da independência funcional é avaliado perante o Executivo, Legislativo e sobre as demais autoridades externas ao MP. Outra questão envolvida na autonomia do MP é a existência de lei ou regulamento que impede outras autoridades (executivas ou legislativas) de dirigir instruções específicas a um membro do MP para processar ou não processar um

32 CEPEJ. The European Commission for the Efficiency of Justice. European judicial systems Efficiency and quality of justice. CEPEJ Studies No. 23, Edition 2016 (2014 data), 2016.

33 CEPEJ. The European Commission for the Efficiency of Justice. European judicial systems Efficiency and quality of justice. CEPEJ Studies No. 23, Edition 2016 (2014 data), 2016. 
LIMAS TOMIO, Fabrício Ricardo de; ROBL FILHO, Ilton Norberto. Autonomia e prerrogativas do ministério público brasileiro em perspectiva comparada: construindo um índice de independência/autonomia. Revista Eletrônica Direito e Política, Programa de Pós-Graduação Stricto Sensu em Ciência Jurídica da UNIVALI, Itajaí, v.16, n.3, 30 quadrimestre de 2021. Disponível em: www.univali.br/direitoepolitica - ISSN 1980-7791.

investigado. No relatório do $C E P E J^{34}$, existem preocupações teóricas e práticas que diferenciam a independência do Judiciário da autonomia do MP em um Estado de Direito (rule of law):

No Estado de Direito, os juízes são independentes dos poderes executivo e legislativo. A situação é mais complexa em relação aos promotores públicos, cujo status difere significativamente entre os Estados. No entanto, esta afirmação também deve ser qualificada porque em alguns Estados, a independência do Ministério Público em relação ao poder político pode ser confirmada no nível estatutário/legal, mas não corresponde à realidade à luz da tradição histórica de dependência do Ministério Público. Em outros Estados, ao contrário, a independência não é reconhecida na legislação, mas a tradição e a prática cotidiana demonstram uma independência real de fato. ${ }^{35}$

No caso do Brasil, a instituição é independente dos demais poderes e autoridades externas. Nesse sentido, por exemplo, compete a Conselho Nacional do Ministério Público o controle "da atuação administrativa e financeira do Ministério Público e do cumprimento dos deveres funcionais de seus membros", segundo o artigo 130-A, $\S$ $2^{\circ}, \mathrm{CF} / 88$. De outro lado, trata-se de um órgão administrativo do próprio Ministério Público, sendo 8 dos seus 14 membros originários dos próprios quadros do Ministério Público da União e dos Estados e Distrito Federal.

A independência do MP vem se tornando um padrão na Europa, com a legislação nacional sendo alterada. Podemos entender melhor essa questão com o item do

${ }^{34}$ CEPEJ. The European Commission for the Efficiency of Justice. European judicial systems Efficiency and quality of justice. CEPEJ Studies No. 23, Edition 2016 (2014 data), 2016.

35 Tradução livre do seguinte trecho: "In a state governed by the rule of law, judges are independent from the executive and legislative power. The situation is more complex regarding public prosecutors, whose status differs significantly across states. However this statement must also be qualified because in some states, the independence of the public prosecution from the political power may be confirmed at the statutory level, but does not correspond to reality in the light of the historical tradition of public prosecutors' dependency. In other states, on the contrary, independence is not recognized in legal acts, but the tradition and daily practice demonstrate a real de facto independence" CEPEJ. The European Commission for the Efficiency of Justice. European judicial systems - Efficiency and quality of justice. CEPEJ Studies No. 23, Edition 2016 (2014 data), 2016.. 
LIMAS TOMIO, Fabrício Ricardo de; ROBL FILHO, Ilton Norberto. Autonomia e prerrogativas do ministério público brasileiro em perspectiva comparada: construindo um índice de independência/autonomia. Revista Eletrônica Direito e Política, Programa de Pós-Graduação Stricto Sensu em Ciência Jurídica da UNIVALI, Itajaí, v.16, n.3, 30 quadrimestre de 2021. Disponível em: www.univali.br/direitoepolitica - ISSN 1980-7791.

relatório do CEPEJ sobre a regulamentação para prevenir instruções específicas para processar (ou não) dirigida a um procurador de justiça em um tribunal:

O contexto institucional do Ministério Público e, em particular, as suas relações com o Executivo variam consoante o Estado ou entidade. No entanto, o princípio da independência funcional dos procuradores está a emergir como uma garantia essencial que se tornou uma verdadeira norma europeia. Essa independência é avaliada face ao executivo, ao legislativo, mas também a todas as outras autoridades externas (...), bem como em termos do modelo de organização do Ministério Público (independência interna) $)^{36}$.

Outro critério presente e enfatizado no relatório do CEPEJ é relativo à vitaliciedade/estabilidade (nomeação e duração do mandato) dos membros do Ministério Público [item (3), do nosso índice], restando clara a prescrição de que a independência depende da garantia da permanência no cargo e na carreira:

Após um período probatório, que normalmente é destinado à formação, os procuradores europeus desempenham predominantemente as suas funções até a aposentadoria por idade, o que é uma importante garantia de continuidade, permitindo autonomia funcional e facilitando a independência ${ }^{37}$.

No Brasil, conforme já descrito, existem constitucionalmente as garantias da vitaliciedade, da inamovibilidade e da irredutibilidade de salários, vencimentos e subsídios, de acordo com o artigo 128, § 50, I, CF/88.

\footnotetext{
36 Tradução livre de: "The institutional context of the prosecution service and particularly its relations with the executive vary according to the State or entity. However, the principle of functional independence of prosecutors is emerging as an essential guarantee which has become a true European standard. This independence is assessed vis-à-vis the executive, the legislative, but also all other external authorities (...), as well as in terms of the organization model of the public prosecution service (internal independence)" CEPEJ. The European Commission for the Efficiency of Justice. European judicial systems - Efficiency and quality of justice. CEPEJ Studies No. 23, Edition 2016 (2014 data), 2016.

37 Tradução livre de: "After a probationary period, which is usually aimed at training, European public prosecutors overwhelmingly perform their functions until the age of retirement, which is an important guarantee of continuity, enabling functional autonomy and facilitating independence" CEPEJ. The European Commission for the Efficiency of Justice. European judicial systems - Efficiency and quality of justice. CEPEJ Studies No. 23, Edition 2016 (2014 data), 2016..
} 
LIMAS TOMIO, Fabrício Ricardo de; ROBL FILHO, Ilton Norberto. Autonomia e prerrogativas do ministério público brasileiro em perspectiva comparada: construindo um índice de independência/autonomia. Revista Eletrônica Direito e Política, Programa de Pós-Graduação Stricto Sensu em Ciência Jurídica da UNIVALI, Itajaí, v.16, n.3, $3^{\circ}$ quadrimestre de 2021. Disponível em: www.univali.br/direitoepolitica - ISSN 1980-7791.

O CEPEJ também reflete e analisa o papel e as atribuições dos promotores e procuradores em 14 itens distintos de atuação, competência e independência funcional [conforme o descrito no item (4) do Quadro A1, no Anexo]. Um desses papéis é a competência para encerrar ou arquivar um caso, impondo ou negociando a penalidade ou medida, sem requerer uma decisão judicial. Dos 46 países europeus, 24 fixam tal competência ao promotor ${ }^{38}$. No caso brasileiro, por exemplo, compete ao Ministério Público "promover o inquérito civil e a ação civil pública, para a proteção do patrimônio público e social, do meio ambiente e de outros interesses difusos e coletivos", nos termos do artigo 129, III, CF/88. A Lei no. 7.347/1985, que disciplina as ações civis públicas, permite que "órgãos públicos legitimados poderão tomar dos interessados compromisso de ajustamento de sua conduta às exigências legais, mediante cominações, que terá eficácia de título executivo extrajudicial", segundo o artigo 50, §60, desse diploma legal. De outro lado, na transação das ações de improbidade administrativa, o Ministério Público pode celebrar acordo, porém necessita de homologação judicial, conforme o artigo 17-B, $\S 10$, Lei Federal no. 8.429/1992 com alteração da Lei no. 14.230/2021 ${ }^{39}$. Também no acordo de não persecução penal, nos termos do artigo do Código de Processo Penal, que foi alterado pela Lei Federal no. 13.964/2019, o Ministério Público, o investigado e seu defensor formalizam o acordo, o qual deve ser homologado judicial, de acordo com o artigo $28-\mathrm{A}, \S \S 20$ a $8^{040}$.

${ }^{38}$ CEPEJ. The European Commission for the Efficiency of Justice. European judicial systems Efficiency and quality of justice. CEPEJ Studies No. 23, Edition 2016 (2014 data), 2016.

39 "Art. 17-B. O Ministério Público poderá, conforme as circunstâncias do caso concreto, celebrar acordo de não persecução civil, desde que dele advenham, ao menos, os seguintes resultados: (Incluído pela Lei no 14.230, de 2021) I - o integral ressarcimento do dano; (Incluído pela Lei no 14.230, de 2021) II - a reversão à pessoa jurídica lesada da vantagem indevida obtida, ainda que oriunda de agentes privados. (Incluído pela Lei no 14.230, de 2021) $\S 10$ A celebração do acordo a que se refere o caput deste artigo dependerá, cumulativamente: (Incluído pela Lei no 14.230, de 2021) I - da oitiva do ente federativo lesado, em momento anterior ou posterior à propositura da ação; (Incluído pela Lei no 14.230, de 2021) II - de aprovação, no prazo de até 60 (sessenta) dias, pelo órgão do Ministério Público competente para apreciar as promoções de arquivamento de inquéritos civis, se anterior ao ajuizamento da ação; (Incluído pela Lei no 14.230, de 2021) III - de homologação judicial, independentemente de o acordo ocorrer antes ou depois do ajuizamento da ação de improbidade administrativa".

40 "§ 20 O disposto no caput deste artigo não se aplica nas seguintes hipóteses: I - se for cabível transação penal de competência dos Juizados Especiais Criminais, nos termos da lei; II - se o investigado for reincidente ou se houver elementos probatórios que indiquem conduta criminal habitual, reiterada 
LIMAS TOMIO, Fabrício Ricardo de; ROBL FILHO, Ilton Norberto. Autonomia e prerrogativas do ministério público brasileiro em perspectiva comparada: construindo um índice de independência/autonomia. Revista Eletrônica Direito e Política, Programa de Pós-Graduação Stricto Sensu em Ciência Jurídica da UNIVALI, Itajaí, v.16, n.3, 30 quadrimestre de 2021. Disponível em: www.univali.br/direitoepolitica - ISSN 1980-7791.

O Ministério Público no Brasil possui as seguintes prerrogativas e competências descritas pelo CEPEJ $^{41}$ para a independência e a autonomia da instituição, como: a) poder conduzir ou supervisionar a investigação policial, b) realizar investigações, quando necessário, c) solicitar medidas de investigação ao juiz, d) acusar e propor ações judiciais, e) formular pedidos que devem ser julgados por sentença judicial, $f$ ) apelar e recorrer, g) supervisionar e fiscalizar o processo de execução e h) outros poderes significativos como funções em casos civis, administrativos e de insolvência, assim como a vítima pode contestar uma decisão do promotor público, conforme se observa especialmente nas funções institucionais constitucionais previstas no artigo 129, I a IX, CF/8842 e na legislação especial como a Lei Federal no. 7.210/1984 ${ }^{43}$, a

ou profissional, exceto se insignificantes as infrações penais pretéritas; III - ter sido o agente beneficiado nos 5 (cinco) anos anteriores ao cometimento da infração, em acordo de não persecução penal, transação penal ou suspensão condicional do processo; e IV - nos crimes praticados no âmbito de violência doméstica ou familiar, ou praticados contra a mulher por razões da condição de sexo feminino, em favor do agressor. $\S 3^{\circ} \mathrm{O}$ acordo de não persecução penal será formalizado por escrito e será firmado pelo membro do Ministério Público, pelo investigado e por seu defensor. § 40 Para a homologação do acordo de não persecução penal, será realizada audiência na qual o juiz deverá verificar a sua voluntariedade, por meio da oitiva do investigado na presença do seu defensor, e sua legalidade. $\S 50$ Se o juiz considerar inadequadas, insuficientes ou abusivas as condições dispostas no acordo de não persecução penal, devolverá os autos ao Ministério Público para que seja reformulada a proposta de acordo, com concordância do investigado e seu defensor. $\S 6^{\circ}$ Homologado judicialmente o acordo de não persecução penal, o juiz devolverá os autos ao Ministério Público para que inicie sua execução perante 0 juízo de execução penal. $\S 70 \mathrm{O}$ juiz poderá recusar homologação à proposta que não atender aos requisitos legais ou quando não for realizada a adequação a que se refere o $\S 5^{\circ}$ deste artigo. $\S 8^{\circ}$ Recusada a homologação, o juiz devolverá os autos ao Ministério Público para a análise da necessidade de complementação das investigações ou o oferecimento da denúncia".

${ }^{41}$ CEPEJ. The European Commission for the Efficiency of Justice. European judicial systems

- Efficiency and quality of justice. CEPEJ Studies No. 23, Edition 2016 (2014 data), 2016. p. 124

42 "I - promover, privativamente, a ação penal pública, na forma da lei; II - zelar pelo efetivo respeito dos Poderes Públicos e dos serviços de relevância pública aos direitos assegurados nesta Constituição, promovendo as medidas necessárias a sua garantia; III - promover o inquérito civil e a ação civil pública, para a proteção do patrimônio público e social, do meio ambiente e de outros interesses difusos e coletivos; IV - promover a ação de inconstitucionalidade ou representação para fins de intervenção da União e dos Estados, nos casos previstos nesta Constituição; V - defender judicialmente os direitos e interesses das populações indígenas; VI - expedir notificações nos procedimentos administrativos de sua competência, requisitando informações e documentos para instruí-los, na forma da lei complementar respectiva; VII - exercer o controle externo da atividade policial, na forma da lei complementar mencionada no artigo anterior; VIII - requisitar diligências investigatórias e a instauração de inquérito policial, indicados os fundamentos jurídicos de suas manifestações processuais; IX - exercer outras funções que the forem conferidas, desde que compatíveis com sua finalidade, sendo-lhe vedada a representação judicial e a consultoria jurídica de entidades públicas".

43 "Art. 67. O Ministério Público fiscalizará a execução da pena e da medida de segurança, oficiando no processo executivo e nos incidentes da execução". 
LIMAS TOMIO, Fabrício Ricardo de; ROBL FILHO, Ilton Norberto. Autonomia e prerrogativas do ministério público brasileiro em perspectiva comparada: construindo um índice de independência/autonomia. Revista Eletrônica Direito e Política, Programa de Pós-Graduação Stricto Sensu em Ciência Jurídica da UNIVALI, Itajaí, v.16, n.3, $3^{\circ}$ quadrimestre de 2021. Disponível em: www.univali.br/direitoepolitica - ISSN 1980-7791.

Lei Federal no. 7.347/198544, a Lei Federal no. 8.078/199045 e a Lei $11.101 / 2005^{46}$, além de diversas outras leis especiais que estabelecem funções, competências, prerrogativas e poderes ao Ministério Público.

De outro lado, as prerrogativas de i) descontinuar um caso sem precisar de uma decisão de um juiz e de j) encerrar o caso impondo ou negociando uma sanção ou medida sem requerer uma decisão judicial são mitigadas na legislação brasileira, pois, conforme demonstrado acima, a legislação brasileira prevê em diversas oportunidades a necessidade de homologação judicial de acordos. Acerca da descontinuação de um caso sem necessidade de decisão judicial, a Constituição Federal brasileira de 1988, no âmbito da ação penal pública, teve "o condão de extinguir o procedimento ex officio, que podia ser instaurado e julgado pelo órgão jurisdicional, bem como com o procedimento judicialiforme, que era deflagrado por portaria de instauração da autoridade policial" (NASCIMENTO, 2017). Por sua vez, de acordo com o artigo 28, do Código de Processo Penal, que ainda se encontra vigente em razão da ADI no. 630547, "Se o órgão do Ministério Público, ao invés de apresentar

44 "Art. $5^{\circ}$ Têm legitimidade para propor a ação principal e a ação cautelar: (Redação dada pela Lei no 11.448, de 2007) (Vide Lei no 13.105, de 2015) (Vigência) I - o Ministério Público".

45 "Art. 81. A defesa dos interesses e direitos dos consumidores e das vítimas poderá ser exercida em juízo individualmente, ou a título coletivo. Parágrafo único. A defesa coletiva será exercida quando se tratar de: I - interesses ou direitos difusos, assim entendidos, para efeitos deste código, os transindividuais, de natureza indivisível, de que sejam titulares pessoas indeterminadas e ligadas por circunstâncias de fato; II - interesses ou direitos coletivos, assim entendidos, para efeitos deste código, os transindividuais, de natureza indivisível de que seja titular grupo, categoria ou classe de pessoas ligadas entre si ou com a parte contrária por uma relação jurídica base; III - interesses ou direitos individuais homogêneos, assim entendidos os decorrentes de origem comum. Art. 82. Para os fins do art. 81, parágrafo único, são legitimados concorrentemente: (Redação dada pela Lei no 9.008, de 21.3.1995) I - o Ministério Público".

46 Por exemplo, a lei de recuperação judicial, de recuperação extrajudicial e falência faz menção 25 vezes ao Ministério Público.

47 "Ex positis, concedo a medida cautelar requerida para suspender a eficácia do artigo $310, \S 4^{\circ}$, do Código de Processo Penal (CPP), na redação introduzida pela Lei $n^{\circ} 13.964 / 2019$. Conclusão Ex positis, na condição de relator das ADIs 6.298, 6.299, 6.300 e 6305, com as vênias de praxe e pelos motivos expostos: (a) Revogo a decisão monocrática constante das ADIs 6.298, 6.299, 6.300 e suspendo sine die a eficácia, ad referendum do Plenário, (a1) da implantação do juiz das garantias e seus consectários (Artigos $3^{0}-A, 3^{0}-B, 3^{0}-C, 3^{0}-D, 3^{a}-E, 3^{0}-F$, do Código de Processo Penal); e (a2) da alteração do juiz sentenciante que conheceu de prova declarada inadmissível (157, §50, do Código de Processo Penal); (b) Concedo a medida cautelar requerida nos autos da ADI 6305, e suspendo sine die a eficácia, ad referendum do Plenário, (b1) da alteração do procedimento de arquivamento do inquérito policial (28, caput, Código de Processo Penal); (b2) Da liberalização da prisão pela não realização da audiência de custodia no prazo de 24 horas (Artigo 310, §4, do Código de Processo Penal); Nos termos do artigo 10, 
LIMAS TOMIO, Fabrício Ricardo de; ROBL FILHO, Ilton Norberto. Autonomia e prerrogativas do ministério público brasileiro em perspectiva comparada: construindo um índice de independência/autonomia. Revista Eletrônica Direito e Política, Programa de Pós-Graduação Stricto Sensu em Ciência Jurídica da UNIVALI, Itajaí, v.16, n.3, 30 quadrimestre de 2021. Disponível em: www.univali.br/direitoepolitica - ISSN 1980-7791.

a denúncia, requerer o arquivamento do inquérito policial ou de quaisquer peças de informação, o juiz, no caso de considerar improcedentes as razões invocadas, fará remessa do inquérito ou peças de informação ao procurador-geral (...)".

Dessa maneira, o resultado da mensuração dos 47 países europeus e do Brasil, no índice de independência/autonomia do MP, está expresso no Gráfico 6 (e Tabela A1, no Anexo). ${ }^{48}$ Como pode ser visto, o Brasil apresenta quase todas as prerrogativas e garantias atribuídas ao MP de forma plena e duas prerrogativas e garantias observadas parcial e mitigadamente. Ou seja, em comparação com os países europeus e com Israel, a independência e a autonomia do Ministério Público brasileiro encontram-se no primeiro terço mais elevado do índice.

$\S 2^{\circ}$, da Lei n. 9868/95, a concessão desta medida cautelar não interfere nem suspende os inquéritos e os processos em curso na presente data. Aguardem-se as informações já solicitadas aos requeridos, ao Advogado-Geral da União e ao Procurador-Geral da República. Após, retornem os autos para a análise dos pedidos de ingresso na lide dos amici curae e a designação oportuna de audiências públicas. Publique-se. Intimem-se" (STF, ADI nº. 6305, Medida Cautelar, Ministro Luiz Fux, Decisão de 22/01/2020).

48 A pesquisa que gerou a base de dados, adaptados do CEPEJ, e o índice CEPEJ/DIPOL de autonomia/independência do MP foi realizada pelos pesquisadores do Núcleo de Pesquisa "DIRPOLDireito e Política" (PPGD/UFPR), contando com o financiamento do CNPq (Edital 14/2014) e do PROEX/CAPES. Uma versão inicial da base de dados e indicadores da pesquisa, atualizado e revista neste artigo, foi utilizada por outros pesquisadores do DIRPOL/PPGD e fez parte das referências presentes na tese de doutorado de autoria de Jessika T. K Martins (2019), defendida no PPGCP/UFPR. 
LIMAS TOMIO, Fabrício Ricardo de; ROBL FILHO, IIton Norberto. Autonomia e prerrogativas do ministério público brasileiro em perspectiva comparada: construindo um índice de independência/autonomia. Revista Eletrônica Direito e Política, Programa de Pós-Graduação Stricto Sensu em Ciência Jurídica da UNIVALI, Itajaí, v.16, n.3, 30 quadrimestre de 2021. Disponível em: www.univali.br/direitoepolitica - ISSN 1980-7791.

Gráfico 6 - Índice de Independência/Autonomia do Ministério Público (CEPEJ/DIRPOL) Prosecutorial Independence (de jure) - CEPEJ (2016)

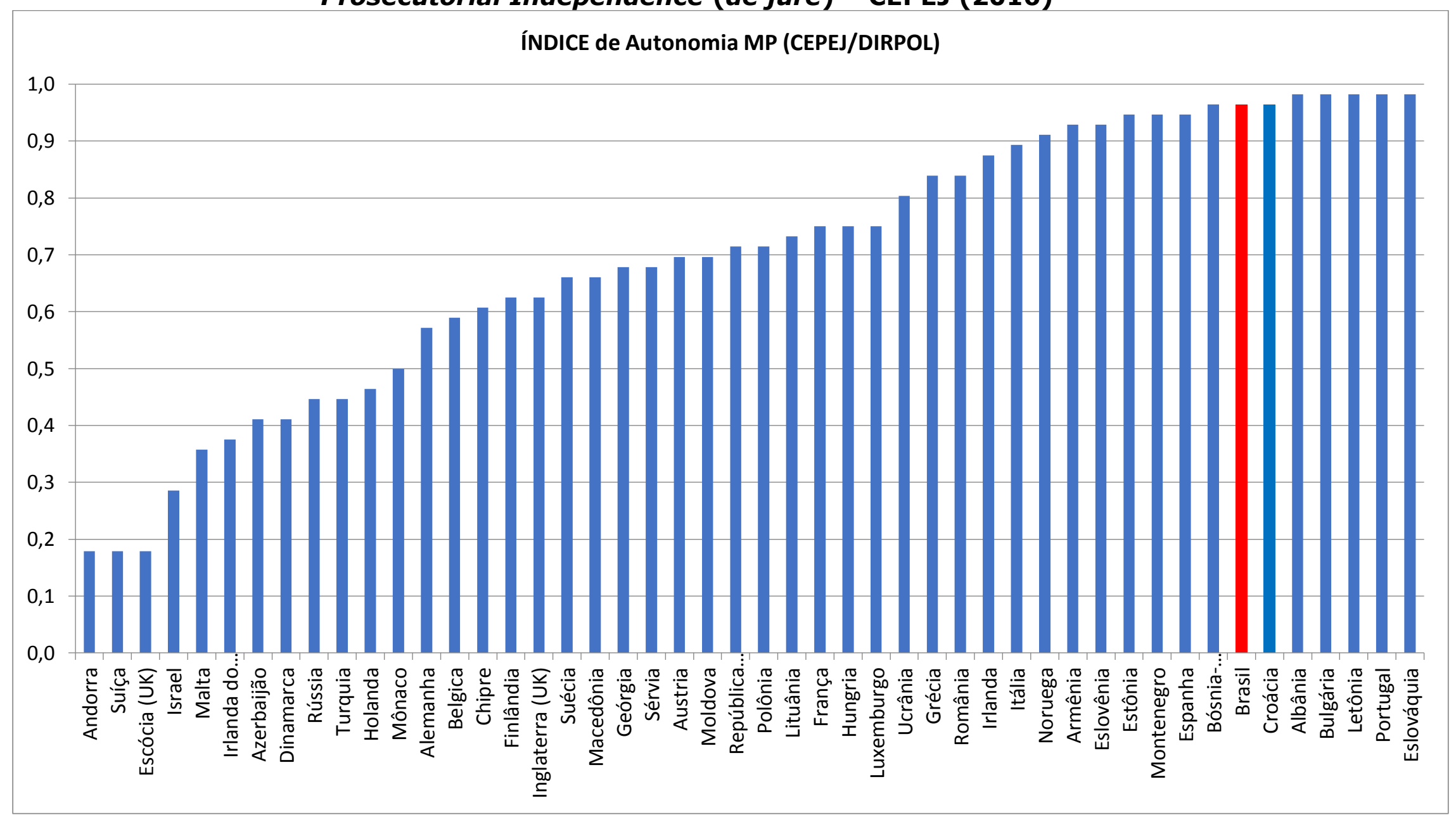

Fonte: Dados para o Brasil definidos pelos pesquisadores do Núcleo de Pesquisa DIRPOL/PPGD/UFPR com base na constituição e legislação. Dados dos países europeus: (CEPEJ, 2016). 
LIMAS TOMIO, Fabrício Ricardo de; ROBL FILHO, Ilton Norberto. Autonomia e prerrogativas do ministério público brasileiro em perspectiva comparada: construindo um índice de independência/autonomia. Revista Eletrônica Direito e Política, Programa de Pós-Graduação Stricto Sensu em Ciência Jurídica da UNIVALI, Itajaí, v.16, n.3, 30 quadrimestre de 2021. Disponível em: www.univali.br/direitoepolitica - ISSN 1980-7791.

Por fim e na Tabela 1, como uma primeira utilização do índice que construímos, podemos verificar que o agrupamento do índice de independência/autonomia do MP (CEPEJ), escalonando em classes, posicionaria o Brasil, em comparação com os países europeus, como um dos que mais atribui garantias e prerrogativas estatutárias ao Ministério Público.

\section{Tabela 1 - Índice de Independência/Autonomia do Ministério Público (CEPEJ/DIRPOL) - por classes (quintis) - Prosecutorial Independence (de jure) - CEPEJ (2016)}

\begin{tabular}{|c|c|c|c|}
\hline $\begin{array}{l}\text { Autonomia } \\
\text { do MP }\end{array}$ & (n) & $(\%)$ & Países \\
\hline 0,0 a 0,2 & 3 & $6,3 \%$ & Andorra, Suíça, Escócia (UK) \\
\hline 0,2 a 0,4 & 3 & $6,3 \%$ & Israel, Malta, Irlanda do Norte (UK) \\
\hline 0,4 a 0,6 & 8 & $16,7 \%$ & $\begin{array}{c}\text { Azerbaijão, Dinamarca, Rússia, Turquia, Holanda, } \\
\text { Mônaco, Alemanha, Belgica }\end{array}$ \\
\hline 0,6 a 0,8 & 15 & $31,3 \%$ & $\begin{array}{c}\text { Chipre, Finlândia, Inglaterra (UK), Suécia, Macedônia, } \\
\text { Geórgia, Sérvia, Austria, Moldova, República Tcheca, } \\
\text { Polônia, Lituânia, França, Hungria, Luxemburgo }\end{array}$ \\
\hline 0,8 a 1,0 & 19 & $39,6 \%$ & $\begin{array}{c}\text { Ucrânia, Grécia, România, Irlanda, Itália, Noruega, } \\
\text { Armênia, Eslovênia, Estônia, Montenegro, Espanha, } \\
\text { Bósnia-Herzegovina, Brasil, Croácia, Albânia, } \\
\text { Bulgária, Letônia, Portugal, Eslováquia }\end{array}$ \\
\hline Total & 48 & $100,0 \%$ & \\
\hline
\end{tabular}

Após a elaboração de índice de (Autonomia, de Jure) do Ministério Público, este texto apresentará relações com os índices do Comparative Constitucions Project.

\section{RELAÇÕES ENTRE O ÍNDICE DE INDEPENDÊNCIA (AUTONOMIA, DE JURE) DO MINISTÉRIO PÚBLICO E OS ÍNDICES DO CCP}

Nos índices do Comparative Constitucions Project (CCP), as competências atribuídas ao Executivo brasileiro podem ser classificadas como moderadas, com o terceiro 
LIMAS TOMIO, Fabrício Ricardo de; ROBL FILHO, Ilton Norberto. Autonomia e prerrogativas do ministério público brasileiro em perspectiva comparada: construindo um índice de independência/autonomia. Revista Eletrônica Direito e Política, Programa de Pós-Graduação Stricto Sensu em Ciência Jurídica da UNIVALI, Itajaí, v.16, n.3, 30 quadrimestre de 2021. Disponível em: www.univali.br/direitoepolitica - ISSN 1980-7791.

maior índice. Por outro lado, o Legislative Power coloca o Brasil entre o 6\% dos países que mais atribui poder constitucionalmente ao Legislativo. Por fim, a constitucionalização da Judicial Independence brasileira se encontra entre o 10\% mais elevado do conjunto de 190 países comparados.

Existe uma tendência de que a constitucionalização de maior independência judicial reste associada à constitucionalização de maior poder do Legislativo e menor poder do Executivo, sendo que, no caso do Brasil, os três poderes (Executivo, Judiciário e Legislativo) têm seus índices semelhantes. No Brasil, os deputados e senadores constituintes de 1988 fixaram de forma elevada a maioria das prerrogativas consideradas pelo $\mathrm{CCP}$, atribuindo substancialmente competências e garantias constitucionalizadas aos poderes estatais.

E quanto ao Ministério Público?

Como o Ministério Público brasileiro possui garantias funcionais, institucionais, orçamentárias quase idênticas àquelas do Judiciário, é lógico afirmar que esses elementos posicionariam o Ministério Público no Brasil, comparativamente, em estrato com elevado grau de independência e autonomia. De fato, nos indicadores de autonomia construídos a partir do $\mathrm{CEPEJ}^{49}$ e do nosso índice CEPEJ/DIRPOL, a independência/autonomia do MP do Brasil está dimensionada no estrato mais elevado, na comparação com 46 países europeus e Israel. Frisa-se que o CEPEJ verifica as garantias de autonomia do Ministério Público, levando em consideração tanto a legislação infraconstitucional como a legislação constitucional nos países avaliados, porém, no caso brasileiro, grande parte das garantias e das competências reside na própria constituição. Em virtude do alto índice de autonomia do Ministério Público no Brasil, a CF/88 transformou esse órgão em importante ator institucional com fortes poderes.

\footnotetext{
${ }^{49}$ CEPEJ. The European Commission for the Efficiency of Justice. European judicial systems
} - Efficiency and quality of justice. CEPEJ Studies No. 23, Edition 2016 (2014 data), 2016. 
LIMAS TOMIO, Fabrício Ricardo de; ROBL FILHO, Ilton Norberto. Autonomia e prerrogativas do ministério público brasileiro em perspectiva comparada: construindo um índice de independência/autonomia. Revista Eletrônica Direito e Política, Programa de Pós-Graduação Stricto Sensu em Ciência Jurídica da UNIVALI, Itajaí, v.16, n.3, 30 quadrimestre de 2021. Disponível em: www.univali.br/direitoepolitica - ISSN 1980-7791.

Correlacionando os resultados do índice do Comparative Constitutional Project e o índice de Prosecutorial Independence (PI, de jure) (VAN AAKEN; FELD; VOIGT, 2010) com o índice de Autonomia do MP que construímos (CEPEJ/DIRPOL), podemos verificar se há alguma regularidade, entre os países comparados, na institucionalização das prerrogativas e garantias do Ministério Público. Quando se correlaciona o nosso índice de autonomia do Ministério Público com os índices apresentados anteriormente para os poderes Executivo, Legislativo e Judiciário (CCP), torna-se possível compreender a relação entre os poderes estatais e esse órgão constitucionalmente autônomo (Ministério Público), buscando possíveis causalidades na institucionalização do grau de autonomia do MP nos países comparados.

No Gráfico 7, percebe-se que a correlação mais significativa (no conjunto de 47 países europeus e o Brasil) entre o índice de autonomia/independência do MP proposto e os índices do CCP encontra-se na associação entre Legislative Power (CCP) e autonomia do MP (CEPEJ/DIRPOL). Ou seja, há uma correlação positiva e fraca, mas existente, entre uma maior constitucionalização de Legislative Power e maior institucionalização de prerrogativas ao MP na amostra analisada. Os demais índices de constitucionalização das instituições (Executive Power e Judicial Independence, CCP) não apresentam uma correlação significativa com a autonomia do MP. 50

50 O resultado da correlação linear (Pearson) e regressão linear $\left(R^{2}\right)$ entre o nosso índice de autonomia/independência do MP (com base nos dados do CEPEJ, 2016) e os outros índices, expostos no Gráfico 7, é o seguinte: com legislative power $\left(r=0,4094 ; \mathrm{R}^{2}=0,1676\right)$; executive power $(r=0,2749$; $\left.\mathrm{R}^{2}=0,0756\right)$; judicial independence $\left(r=0,2174 ; \mathrm{R}^{2}=0,0473\right)$; prosecutor independence $(r=0,5828$; $\left.\mathrm{R}^{2}=0,3397\right)$. 
LIMAS TOMIO, Fabrício Ricardo de; ROBL FILHO, Ilton Norberto. Autonomia e prerrogativas do ministério público brasileiro em perspectiva comparada: construindo um índice de independência/autonomia. Revista Eletrônica Direito e Política, Programa de Pós-Graduação Stricto Sensu em Ciência Jurídica da UNIVALI, Itajaí, v.16, n.3, 30 quadrimestre de 2021. Disponível em: www.univali.br/direitoepolitica - ISSN 1980-7791.

\section{Gráfico 7 - Índice de Independência/Autonomia MP (CEPEJ)/DIRPOL) X Judicial Independence, Executive/Legislative Power (CCP Índices) e} Prosecutorial Independence (PI, de jure) (VAN AAKEN; FELD; VOIGT, 2010)
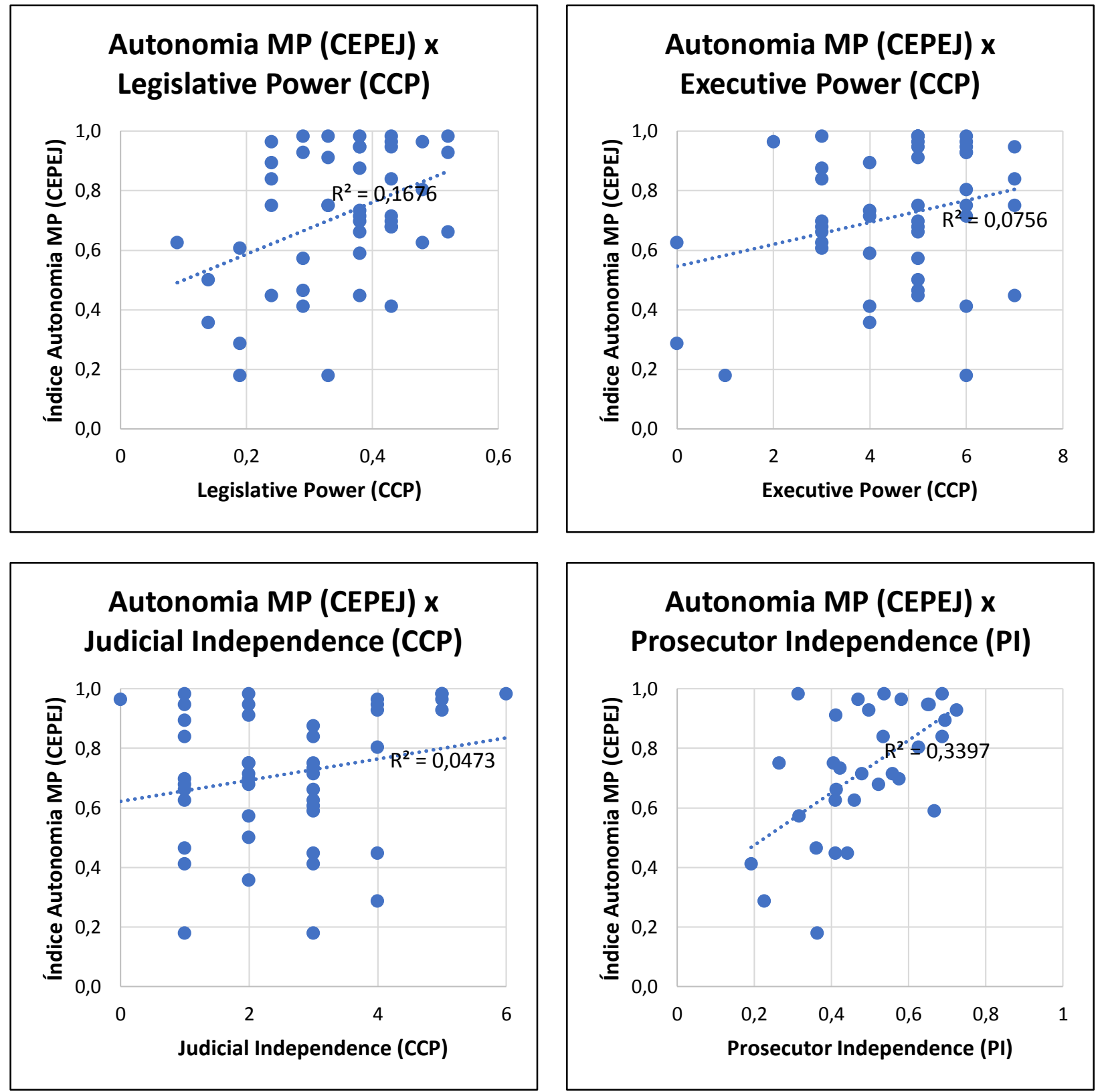

Fonte: Dados para o Brasil definidos pelos pesquisadores do Núcleo de Pesquisa DIRPOL/PPGD/UFPR com base na constituição e legislação. Dados dos países europeus: (CEPEJ; 2016). VAN AAKEN; FELD; VOIGT (2010). 
LIMAS TOMIO, Fabrício Ricardo de; ROBL FILHO, Ilton Norberto. Autonomia e prerrogativas do ministério público brasileiro em perspectiva comparada: construindo um índice de independência/autonomia. Revista Eletrônica Direito e Política, Programa de Pós-Graduação Stricto Sensu em Ciência Jurídica da UNIVALI, Itajaí, v.16, n.3, 30 quadrimestre de 2021. Disponível em: www.univali.br/direitoepolitica - ISSN 1980-7791.

\section{Quadro 1 -Índice de Autonomia MP (CEPEJ/DIRPOL) X Legislative Power (CCP Índices) (por tercis: País; Autonomia MP; Legislative Power)}

\begin{tabular}{|c|c|c|c|}
\hline & $L e$ & tive Power (CC & \\
\hline & 10 Tercil & 20 Tercil & $3^{\circ}$ Tercil \\
\hline 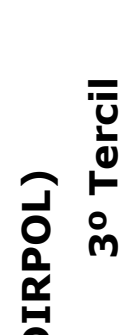 & $\begin{array}{c}\text { Portugal; 0,982; 0,29 } \\
\text { Bósnia-Herzegovina; } \\
\text { 0,964;0,24 } \\
\text { Armênia; 0,929;0,29 } \\
\text { Itália; 0,893;0,24 }\end{array}$ & $\begin{array}{c}\text { Eslováquia; 0,982;0,33 } \\
\text { Letônia; 0,982;0,38 } \\
\text { Estônia; 0,946;0,38 } \\
\text { Espanha; 0,946;0,38 } \\
\text { Noruega; 0,911;0,33 }\end{array}$ & $\begin{array}{c}\text { Albânia; 0,982;0,43 } \\
\text { Bulgária; 0,982;0,52 } \\
\text { Croácia; 0,964;0,43 } \\
\text { Brasil; 0,964;0,48 } \\
\text { Montenegro;0,946; } \\
0,43 \\
\text { Eslovênia; 0,929;0,52 }\end{array}$ \\
\hline 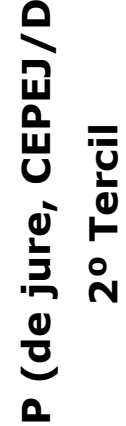 & $\begin{array}{l}\text { Grécia; } 0,839 ; 0,24 \\
\text { França; } 0,750 ; 0,24\end{array}$ & $\begin{array}{c}\text { Irlanda;0,875;0,38 } \\
\text { Hungria;0,750;0,33 } \\
\text { Luxemburgo;0,750; } \\
0,33 \\
\text { Lituânia;0,732;0,38 } \\
\text { República Tcheca; } \\
0,714 ; 0,38 \\
\text { Moldova;0,696;0,38 } \\
\text { Macedônia;0,661;0,38 }\end{array}$ & $\begin{array}{c}\text { România; 0,839; 0,43 } \\
\text { Ucrânia; 0,804;0,48 } \\
\text { Polônia; 0,714;0,43 } \\
\text { Áustria; 0,696;0,43 } \\
\text { Geórgia; 0,679;0,43 } \\
\text { Sérvia; 0,679;0,43 } \\
\text { Suécia; 0,661;0,52 }\end{array}$ \\
\hline 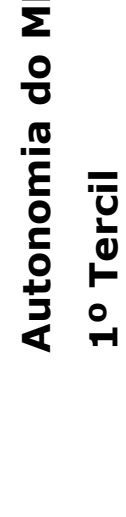 & $\begin{array}{r}\text { Inglaterra (UK);0,625; } \\
\text { 0,09 } \\
\text { Chipre;0,607;0,19 } \\
\text { Alemanha;0,571;0,29 } \\
\text { Mônaco;0,500;0,14 } \\
\text { Holanda; 0,464;0,29 } \\
\text { Rússia; } 0,446 ; 0,24 \\
\text { Azerbaijão; } 0,411 ; 0,29 \\
\text { Malta; } 0,357 ; 0,14 \\
\text { Israel; } 0,286 ; 0,19 \\
\text { Andorra; } 0,179 ; 0,19\end{array}$ & $\begin{array}{c}\text { Belgica; 0,589;0,38 } \\
\text { Turquia; 0,446;0,38 } \\
\text { Suíça; } 0,179 ; 0,33\end{array}$ & $\begin{array}{c}\text { Finlândia; } 0,625 ; 0,48 \\
\text { Dinamarca; } 0,411 ; \\
0,43\end{array}$ \\
\hline
\end{tabular}

Fonte: Dados para o Brasil definidos pelos pesquisadores do Núcleo de Pesquisa DIRPOL/PPGD/UFPR com base na constituição e legislação. Dados dos países europeus: (CEPEJ; 2016). 
LIMAS TOMIO, Fabrício Ricardo de; ROBL FILHO, Ilton Norberto. Autonomia e prerrogativas do ministério público brasileiro em perspectiva comparada: construindo um índice de independência/autonomia. Revista Eletrônica Direito e Política, Programa de Pós-Graduação Stricto Sensu em Ciência Jurídica da UNIVALI, Itajaí, v.16, n.3, 30 quadrimestre de 2021. Disponível em: www.univali.br/direitoepolitica - ISSN 1980-7791.

O índice de prosecutorial independence (PI, de jure), desenvolvido por Van Aaken, Feld e Voigt ${ }^{51}$, possui, como esperado, maior correlação com o índice de autonomia/independência do MP que construímos. Para avançar na análise qualitativa, que não pode ser medida pela correlação linear, realizamos uma estratificação por tercis dos índices de autonomia do MP (CEPEJ/DIRPOL) e Legislative Power (CCP) - (ver Quadro 1). Essa apresentação dos dados reforça a percepção que há maior probabilidade de encontrar um grau mais elevado de prerrogativas e garantias institucionais atribuídas ao MP, quando os países constitucionalizam mais poderes ao Legislativo. A associação é limitada, conforme expresso anteriormente, com grande parte dos países europeus não se enquadrando claramente nessa tendência de atribuir graus semelhantes de poderes ao Legislativo e autonomia institucional ao MP. Porém, da mesma forma, o Brasil se encontra no extremo superior de constitucionalização/institucionalização de prerrogativas ao poder Legislativo ao MP.

\section{Gráfico 7 - Índice de Autonomia MP (CEPEJ/DIRPOL) - Democracias Consolidadas e Recentes}

51 VAN AAKEN, Anne; FELD, Lars P.; VOIGT, Stefan. Do independent prosecutors deter political corruption? An empirical evaluation across seventy-eight countries. American Law and Economics Review, v. 12, n. 1, p. 204-244, 2010. 
LIMAS TOMIO, Fabrício Ricardo de; ROBL FILHO, Ilton Norberto. Autonomia e prerrogativas do ministério público brasileiro em perspectiva comparada: construindo um índice de independência/autonomia. Revista Eletrônica Direito e Política, Programa de Pós-Graduação Stricto Sensu em Ciência Jurídica da UNIVALI, Itajaí, v.16, n.3, 30 quadrimestre de 2021. Disponível em: www.univali.br/direitoepolitica - ISSN 1980-7791.

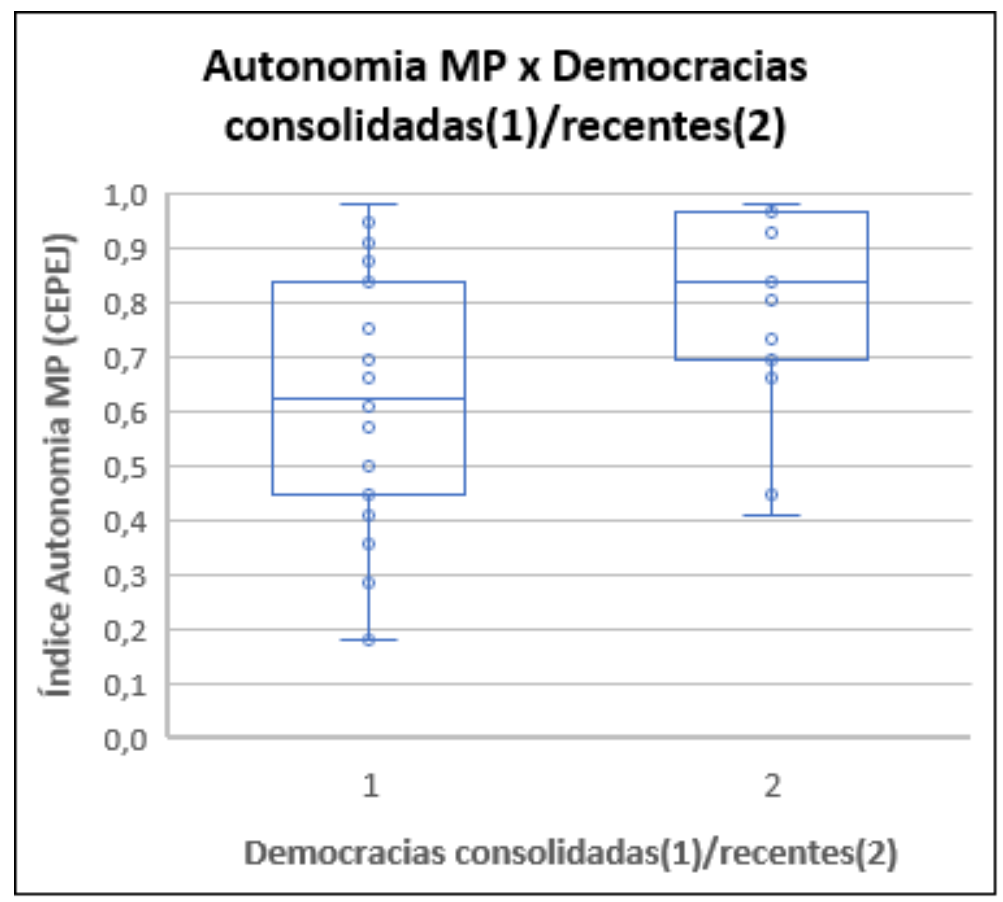

Fonte: Dados para o Brasil definidos pelos pesquisadores do Núcleo de Pesquisa DIRPOL/PPGD/UFPR com base na constituição e legislação. Dados dos países europeus: (CEPEJ; 2016).

Por fim, incluímos mais uma variável na análise, a consolidação da democracia em cada país, entendendo democracias menos consolidadas como aquelas que tiveram longos regimes autoritários (ditadura militar ou socialista) e estabeleceram regimes democráticos através de uma ruptura marcada por novas constituições nos anos 80 e 90 do século passado. Desta forma, se considerarmos democracias consolidadas (1; anteriores a década de 80 ) e recentes ( 2 ; posteriores a década de 80 , Brasil e países do leste europeu com constituições resultantes da queda do muro), é possível ver que há maior probabilidade de encontrar mais garantias e prerrogativas de autonomia institucional atribuída ao MP em "democracias recentes". Isto pode significar que constituições pós anos 80 e de transições mais recentes de regimes autoritários tendem a reforçar as prerrogativas de autonomia do MP (ver Gráfico 8 e Quadro 2). No Quadro 2 é possível ver descritiva e qualitativamente a dispersão apresentada no Gráfico 8. Mesmo havendo muitas democracias recentes (do leste 
LIMAS TOMIO, Fabrício Ricardo de; ROBL FILHO, Ilton Norberto. Autonomia e prerrogativas do ministério público brasileiro em perspectiva comparada: construindo um índice de independência/autonomia. Revista Eletrônica Direito e Política, Programa de Pós-Graduação Stricto Sensu em Ciência Jurídica da UNIVALI, Itajaí, v.16, n.3, 30 quadrimestre de 2021. Disponível em: www.univali.br/direitoepolitica - ISSN 1980-7791.

europeu) com menor grau de institucionalização de autonomia do MP, os índices de autonomia do MP são superiores às democracias consolidadas do mesmo estrato.

\section{Quadro 2 - Índice de Autonomia MP (CEPEJ/DIRPOL) - Democracias Consolidadas e Recentes}

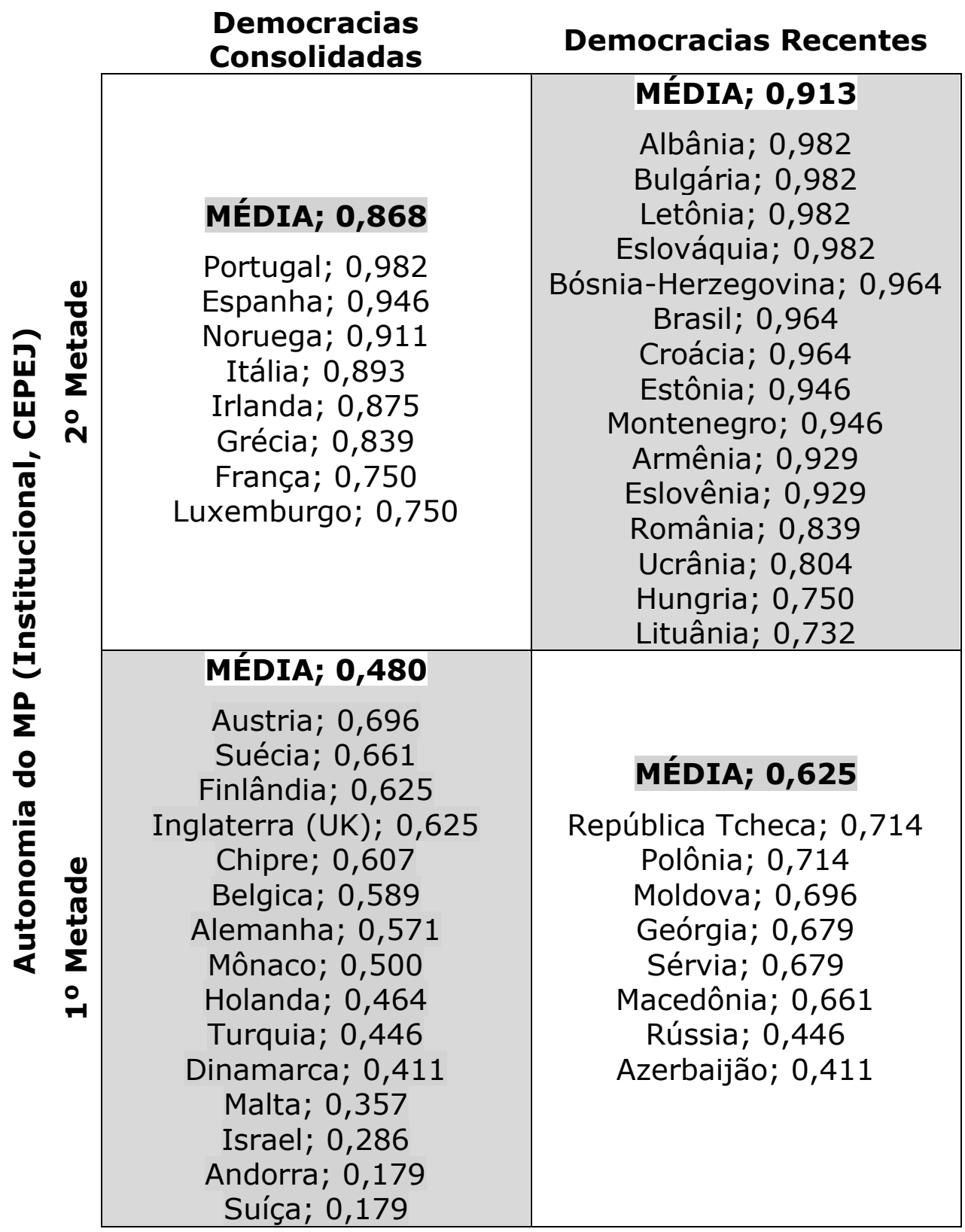


LIMAS TOMIO, Fabrício Ricardo de; ROBL FILHO, Ilton Norberto. Autonomia e prerrogativas do ministério público brasileiro em perspectiva comparada: construindo um índice de independência/autonomia. Revista Eletrônica Direito e Política, Programa de Pós-Graduação Stricto Sensu em Ciência Jurídica da UNIVALI, Itajaí, v.16, n.3, 30 quadrimestre de 2021. Disponível em: www.univali.br/direitoepolitica - ISSN 1980-7791.

Fonte: Dados para o Brasil definidos pelos pesquisadores do Núcleo de Pesquisa DIRPOL/PPGD/UFPR com base na constituição e legislação. Dados dos países europeus: (CEPEJ; 2016).

Esta conclusão é muito importante para o caso do Brasil, pois confirma os poderes atribuídos ao MP na CF/88, que garantiram maior autonomia e independência. A maior quantidade de prerrogativas do MP parece ser um produto que se acentua no período posterior aos anos noventa e está mais fortemente associada à transição de regimes autoritários nesse período, confirmando que a Constituição brasileira de 1988 também trouxe maior constitucionalização para promover mais garantias à autonomia do Ministério Público.

\section{CONSIDERAÇÕES FINAIS}

O artigo tem por objetivo principal desenvolver um índice para mensurar a autonomia e a independência do Ministério Público, permitindo uma análise comparada do Ministério Público brasileiro com outras instituições estatais semelhantes no mundo.

Para realizar esta comparação, inicialmente, utilizamos índices consolidados na literatura que analisam os poderes centrais do Estado (no mesmo país e entre os países comparados): Executivo, Legislativo e Judiciário, que serviram para dimensionar, dentro de um país, a relação entre os poderes e, eventualmente, sugerir uma explicação causal para a independência/autonomia do MP de cada país. Pela abrangência (190 países comparados), utilizamos os índices do CCP (Comparative Constitutions Project). O exame inicial do índice Judicial Independence (CCP) já permite constatar, indireta e comparativamente, a elevada autonomia institucional e constitucional do Ministério Público brasileiro, pois a estrutura constitucional do Judiciário brasileiro é semelhante ao do Ministério Público, sendo um arranjo constitucional incomum à imensa maioria dos 190 Estados nacionais comparados pelo CCP. Os principais achados, em relação ao Brasil, permitem verificar que a constituição brasileira a) garante maior independência/autonomia ao Judiciário do 
LIMAS TOMIO, Fabrício Ricardo de; ROBL FILHO, Ilton Norberto. Autonomia e prerrogativas do ministério público brasileiro em perspectiva comparada: construindo um índice de independência/autonomia. Revista Eletrônica Direito e Política, Programa de Pós-Graduação Stricto Sensu em Ciência Jurídica da UNIVALI, Itajaí, v.16, n.3, 30 quadrimestre de 2021. Disponível em: www.univali.br/direitoepolitica - ISSN 1980-7791.

que poderes à legislatura nacional, mas b) a independência e a autonomia judiciais e os poderes/competências do Legislativo são mais robustos do que os poderes atribuídos ao Executivo. E a maioria esmagadora das garantias do Judiciário brasileiro é estendida constitucionalmente ao Ministério Público.

Em seguida, abordando o objeto central do texto, descrevemos e construímos um índice de independência/autonomia do Ministério Público, além de buscar associações e, eventualmente, causalidades que pudessem sustentar uma explicação para a ampliação, pela CF/1988, das prerrogativas e competências do Ministério Público brasileiro, que, comparativamente, faz desse órgão estatal um dos MP com mais elevado grau de autonomia e independência formal. Para tanto, desenvolvemos um índice de Independência/Autonomia do MP (CEPEJ/DIRPOL) com base em prerrogativas institucionais (de jure), compilando a legislação brasileira e utilizando os dados organizados pelo CEPEJ (The European Commission for the Efficiency of Justice) para 47 países europeus, órgão oficial da Comunidade Europeia. Essa escolha metodológica limitou a comparação, presente neste artigo, do Brasil com países europeus. A ampliação da amostra com países da América Latina é uma das agendas de pesquisa a ser implementada pelo DIRPOL/PPGD. Os primeiros achados, os quais são resultantes do índice, demonstram que o Brasil apresenta quase todas as prerrogativas e garantias atribuídas ao MP de forma plena. Isto é, em comparação com os países europeus, a independência e a autonomia do Ministério Público brasileiro encontram-se no estrato mais elevado do índice, sendo um dos países que mais atribui garantias e prerrogativas constitucionais e estatutárias ao Ministério Público. Situação semelhante àquela descrita na constitucionalização da Judicial Independence brasileira, a qual está entre o $10 \%$ mais elevado do conjunto de 190 países comparados pelo CCP.

Na correlação entre o nosso índice de autonomia/independência do MP e os índices do CCP, um dos principais achados é a associação entre Legislative Power (CCP) e autonomia do MP (CEPEJ/DIRPOL). Isto é, há uma correlação positiva e fraca, mas existente entre uma maior constitucionalização de Legislative Power e maior 
LIMAS TOMIO, Fabrício Ricardo de; ROBL FILHO, Ilton Norberto. Autonomia e prerrogativas do ministério público brasileiro em perspectiva comparada: construindo um índice de independência/autonomia. Revista Eletrônica Direito e Política, Programa de Pós-Graduação Stricto Sensu em Ciência Jurídica da UNIVALI, Itajaí, v.16, n.3, 30 quadrimestre de 2021. Disponível em: www.univali.br/direitoepolitica - ISSN 1980-7791.

institucionalização de prerrogativas ao MP na amostra analisada. Esse achado reforça a percepção, ainda que estatisticamente limitada, sobre a maior probabilidade de encontrar um grau mais elevado de prerrogativas e garantias institucionais atribuídas ao MP, quando os países constitucionalizam mais poderes ao Legislativo.

Por fim, introduzimos mais uma variável na análise para compreender o grau de autonomia/independência do MP na amostra de países comparados: a consolidação da democracia. Considerando a classificação de democracias consolidadas e recentes, foi verificado que há maior probabilidade de existir mais garantias e prerrogativas de autonomia institucional atribuída ao MP em "democracias recentes". Uma interpretação possível desse achado é que os constituintes nas transições mais recentes de regimes autoritários tenderam a reforçar as prerrogativas de autonomia do Ministério Público. Mesmo salientando o limite explanatório dessa observação descritiva das frequências na amostra, esta associação entre democracias recentes e grau de autonomia do MP é muito importante para o caso do Brasil, porque confirma os poderes atribuídos ao MP na CF/88, que garantiram maior autonomia e independência.

\section{REFERÊNCIAS BIBLIOGRÁFICAS}

CARVALHO, Ernani; LEITAO, Natalia. O Novo desenho institucional do Ministério Publico e o Processo de Judicialização da Política [online]. 2010. Disponível em: http://www.scielo.br/pdf/rdgv/v6n2/a03v6n2.pdf. Acesso em 03.11.2021.

CARVALHO, Ernani; LEITAO, Natalia. Operationalizing and Measuring Prosecutorial Independence: The Brazilian Case. In: INGRAM, Matthew C.; KAPISZEWSKI, Diana. (Org.). Beyond High Courts: The Justice Complex in Latin America. Indiana: Notre Dame Press, 2019, v. 1, p. 81-112.

CEPEJ. The European Commission for the Efficiency of Justice. European judicial systems - Efficiency and quality of justice. CEPEJ Studies No. 23, Edition 2016 (2014 data), 2016.

DIAS, Paulo J.; AZEVEDO, Rodrigo G. de. O papel do Ministério Público: estudos comparados dos países latino-americanos. São Paulo: Almedina, 2008. 
LIMAS TOMIO, Fabrício Ricardo de; ROBL FILHO, Ilton Norberto. Autonomia e prerrogativas do ministério público brasileiro em perspectiva comparada: construindo um índice de independência/autonomia. Revista Eletrônica Direito e Política, Programa de Pós-Graduação Stricto Sensu em Ciência Jurídica da UNIVALI, Itajaí, v.16, n.3, 30 quadrimestre de 2021. Disponível em: www.univali.br/direitoepolitica - ISSN 1980-7791.

ELKINS, Zachary; GINSBURG, Tom; MELTON, James. The comparative constitutions project: A cross-national historical dataset of written constitutions. Chicago: Mimeo, 2009a.

ELKINS, Zachary; GINSBURG, Tom; MELTON, James. The endurance of national constitutions. Cambridge-UK: Cambridge University Press, 2009b.

ELKINS, Zachary; GINSBURG, Tom; MELTON, James. Constitutional constraints on executive lawmaking. Working paper, 2012. Disponível em: http://citeseerx.ist.psu.edu/viewdoc/summary?doi=10.1.1.434.9346. Acesso em 11.10.2021.

FISH, M. Steven; KROENIG, Matthew. The handbook of national legislatures: A global survey. Cambridge-UK: Cambridge University Press, 2009.

GUTMANNN, Jerg; VOIGT, Stefan: The Independence of Prosecutors and Government Accountability. ILE Working Paper Series, No. 8, University of Hamburg, Institute of Law and Economics (ILE), Hamburg, 2017.

MARTINS, Jessika Torres Kaminski. Ministério Público, autonomia e competências: estudo comparado e o caso do MPT na esfera da discriminação. 2019. Tese (Doutorado em Ciência Política) - Universidade Federal do Paraná.

MAZZILLI, Hugo Nigro. A independência do Ministério Público. Palestra proferida na Associação do Ministério Público do Rio de Janeiro em 11.03.1996. transcrita em Juris Síntese Millennium [Cd-rom]: Síntese, jan 2001). Disponível em: http://www.mazzilli.com.br/pages/artigos/indmp.pdf. Acesso em 11.10.2021.

MELTON, James; GINSBURG, Tom. Does de jure judicial independence really matter? A reevaluation of explanations for judicial independence. Journal of Law and Courts, v. 2, n. 2, p. 187-217, 2014.

MORAES, Alexandre. Direito Constitucional. 13 ed. São Paulo: Atlas, 2003.

SADEK, Maria Tereza. A Construção de um novo Ministério Público resolutivo. De jure: Revista Jurídica do Ministério Público do Estado de Minas Gerais, Belo Horizonte, n. 12, p. 130-139, 2009.

STF, ADI no. 6305, Medida Cautelar, Ministro Luiz Fux, Decisão de 22/01/2020.

VAN AAKEN, Anne; FELD, Lars P.; VOIGT, Stefan. Do independent prosecutors deter political corruption? An empirical evaluation across seventy-eight countries. American Law and Economics Review, v. 12, n. 1, p. 204-244, 2010. 
LIMAS TOMIO, Fabrício Ricardo de; ROBL FILHO, Ilton Norberto. Autonomia e prerrogativas do ministério público brasileiro em perspectiva comparada: construindo um índice de independência/autonomia. Revista Eletrônica Direito e Política, Programa de Pós-Graduação Stricto Sensu em Ciência Jurídica da UNIVALI, Itajaí, v.16, n.3, 30 quadrimestre de 2021. Disponível em: www.univali.br/direitoepolitica - ISSN 1980-7791.

VOIGT, Stefan; WULF, Alexander J. What makes prosecutors independent? Analysing the institutional determinants of prosecutorial independence. Journal of Institutional Economics, p. 1-22, 2017. 
LIMAS TOMIO, Fabrício Ricardo de; ROBL FILHO, Ilton Norberto. Autonomia e prerrogativas do ministério público brasileiro em perspectiva comparada: construindo um índice de independência/autonomia. Revista Eletrônica Direito e Política, Programa de Pós-Graduação Stricto Sensu em Ciência Jurídica da UNIVALI, Itajaí, v.16, n.3, 30 quadrimestre de 2021. Disponível em: www.univali.br/direitoepolitica - ISSN 1980-7791.

\section{ANEXOS}

Quadro A1 - Indicadores - Índice (de jure) de Independência/Autonomia do Ministério Público (MP) comparado (adaptado de CEPEJ, 2016/DIRPOL)

\section{Indicadores / Índice de autonomia MP comparada (adaptado de CEPEJ, 2016)}

(1) Estatuto dos procuradores públicos / Status of public prosecutors $(0-1)$ : 1.1Estatutariamente independente / Statutorily independente ( $1=y e s$; $0=\varnothing)$

1.2Sob o Ministério da Justiça ou outra autoridade central / Under the Ministry of Justice or another central authority $(-0,5=$ yes $)$ 1.30 utro / Other $(-0,5=$ yes $)$

(2) Regulamento para evitar instruções específicas para processar ou não, dirigido a um procurador em um tribunal? / Regulation to prevent specific instructions to prosecute or not, addressed to a prosecutor in a court? $(1=$ yes; $0=\varnothing)$

(3) Mandato do Ministério Público / Term of office of prosecutors (0 - 1):

3.1Compromisso até a aposentadoria / Appointment until retirement $(1=$ yes; $0=\varnothing)$

3.2Contrato Renovável / Renewable contract $(-0,5=y e s)$

(4) Papel do Ministério Público / Role of public prosecutor (14 itens; $x=\Sigma y e$ s. $_{1}$ 14/14)

4.1 Papel do procurador para conduzir ou supervisionar a investigação policial / Role of public prosecutor - to conduct or supervise police investigation $(1 / 14=y e s ; 0=\varnothing)$

4.2 Papel do procurador para conduzir investigações / Role of public prosecutor - to conduct investigations $(1 / 14=y e s ; 0=\varnothing)$

4.3 Papel do ministério público - quando necessário para solicitar medidas de investigação do juiz / Role of public prosecutor- when necessary, to request investigation measures from the judge $(1 / 14=y e s ; 0=\varnothing)$

4.4 Papel do procurador público para acusar / Role of public prosecutorto charge $(1 / 14=y e s ; 0=\varnothing)$

4.5 Papel do procurador público - apresentar o caso em tribunal / Role of public prosecutor- to present the case in court $(1 / 14=y e s ; 0=\varnothing)$

4.6 Papel do procurador público - propor uma sentença ao juiz / Role of public prosecutor- to propose a sentence to the judge $(1 / 14=y e s ;$ $0=\varnothing)$

4.7 Papel do procurador público para apelar / Role of public prosecutorto appeal $(1 / 14=y e s ; 0=\varnothing)$

4.8 Papel do procurador público para supervisionar o processo de execução / Role of public prosecutor- to supervise the enforcement procedure $(1 / 14=y e s ; 0=\varnothing)$ 
LIMAS TOMIO, Fabrício Ricardo de; ROBL FILHO, Ilton Norberto. Autonomia e prerrogativas do ministério público brasileiro em perspectiva comparada: construindo um índice de independência/autonomia. Revista Eletrônica Direito e Política, Programa de Pós-Graduação Stricto Sensu em Ciência Jurídica da UNIVALI, Itajaí, v.16, n.3, 30 quadrimestre de 2021. Disponível em: www.univali.br/direitoepolitica - ISSN 1980-7791.

4.9 Papel do promotor público - descontinuar um caso sem precisar de uma decisão de um juiz / Role of public prosecutor- to discontinue a case without needing a decision by a judge $(1 / 14=y e s ; 0=\varnothing)$

4.10 Papel do promotor público encerra o caso impondo ou negociando uma sanção ou medida sem exigir uma decisão judicial / Role of public prosecutor- end the case by imposing or negotiating a penalty or measure without requiring a judicial decision $(1=y e s ; 0=\varnothing)$

4.11 Papel do procurador público - outros poderes significativos / Role of public prosecutor- other significant powers $(1 / 14=y e s ; 0=\varnothing)$

4.12 Papel em processos civis e adminsitrativos / Role in civil and administrative cases $(1 / 14=y e s ; 0=\varnothing)$

4.13 Papel do procurador público em casos de insolvência - Role of public prosecutor- role in insolvency cases $(1 / 14=y e s ; 0=\varnothing)$

4.14 Papel do procurador público - A vítima pode contestar uma decisão do promotor público / Role of public prosecutor- The victim can dispute a decision of the public prosecuctor $(1 / 14=y e s ; 0=\varnothing)$

Fonte: Organizado pelos pesquisadores do DIRPOL/PPGD/UFPR com base nos parâmetros propostos pelo CEPEJ (2016) para avaliar a autonomia do Ministério Público. 
LIMAS TOMIO, Fabrício Ricardo de; ROBL FILHO, Ilton Norberto. Autonomia e prerrogativas do ministério público brasileiro em perspectiva comparada: construindo um índice de independência/autonomia. Revista Eletrônica Direito e Política, Programa de Pós-Graduação Stricto Sensu em Ciência Jurídica da UNIVALI, Itajaí, v.16, n.3, $3^{0}$ quadrimestre de 2021. Disponível em: www.univali.br/direitoepolitica ISSN 1980-7791.

Tabela A1 - Dados e Índice de Independência/Autonomia do MP - Prosecutorial Independence (de jure) [CEPEJ/DIRPOL]

\begin{tabular}{|c|c|c|c|c|c|c|c|c|c|}
\hline sa & População & $\begin{array}{c}\text { Despesa } \\
\text { Total } \\
\text { MP( } \\
(\text { milhõe } \\
\text { s } €)^{(*)}\end{array}$ & $\begin{array}{c}\text { Despes } \\
\text { a por } \\
\text { hab do } \\
\text { MP } \\
(2015 . \\
\text { CNMP) } \\
(€)^{(*)}\end{array}$ & $\begin{array}{l}\text { Salário } \\
\text { Bruto } \\
\text { Anual } \\
\text { Promotor } \\
\text { Público - } \\
\text { Início de } \\
\text { Carreira } \\
(€){ }^{(*)}\end{array}$ & $\begin{array}{c}\text { ÍNDICE de } \\
\text { Independênci } \\
\text { a/ } \\
\text { Autonomia do } \\
\text { MP } \\
\text { (CEPEJ/DIRP } \\
\text { OL) }\end{array}$ & ${\underset{(* *}{(* *}}_{(1}^{(1}$ & $\begin{array}{c}\mathbf{2} \\
(* * \\
)\end{array}$ & $\begin{array}{c}\mathbf{3} \\
(* * \\
)\end{array}$ & $\begin{array}{l}(4) \\
(* *)\end{array}$ \\
\hline Albânia & 2.893 .005 & 11,88 & 4,11 & 8.988 & 0,982 & 1,0 & 1,0 & 1,0 & $\begin{array}{c}0,92 \\
9\end{array}$ \\
\hline Alemanha & 80.780 .728 & 523,35 & 6,48 & 45.294 & 0,571 & 0,5 & 0,0 & 1,0 & $\begin{array}{c}0,78 \\
6\end{array}$ \\
\hline Andorra & 76.949 & 0,67 & 8,70 & 73.877 & 0,179 & 0,0 & 0,0 & 0,0 & $\begin{array}{c}0,71 \\
4\end{array}$ \\
\hline Armênia & 3.010 .600 & 6,87 & 2,28 & -- & 0,929 & 1,0 & 1,0 & 1,0 & $\begin{array}{c}0,71 \\
4\end{array}$ \\
\hline Áustria & 8.584 .926 & -- & -- & 53.486 & 0,696 & 0,0 & 1,0 & 1,0 & $\begin{array}{c}0,78 \\
6\end{array}$ \\
\hline Azerbaijão & 9.477 .100 & 51,88 & 5,47 & 6.427 & 0,411 & 0,5 & 0,0 & 0,5 & $\begin{array}{c}0,64 \\
3\end{array}$ \\
\hline Belgica & 11.209 .044 & -- & -- & 66.182 & 0,589 & 0,5 & 0,0 & 1,0 & $\begin{array}{c}0,85 \\
7\end{array}$ \\
\hline $\begin{array}{c}\text { Bósnia- } \\
\text { Herzegovi } \\
\text { na }\end{array}$ & 3.827 .343 & 23,72 & 6,20 & 23.884 & 0,964 & 1,0 & 1,0 & 1,0 & $\begin{array}{c}0,85 \\
7\end{array}$ \\
\hline Brasil & $\begin{array}{c}204.450 .6 \\
49\end{array}$ & $\begin{array}{c}4.825,0 \\
4\end{array}$ & 23,60 & 95.560 & 0,964 & $\begin{array}{c}1, \\
0\end{array}$ & $\begin{array}{l}1, \\
0\end{array}$ & $\begin{array}{l}1, \\
0\end{array}$ & $\begin{array}{c}0,85 \\
7\end{array}$ \\
\hline Bulgária & 7.202 .198 & 93,70 & 13,01 & 15.317 & 0,982 & 1,0 & 1,0 & 1,0 & $\begin{array}{c}0,92 \\
9\end{array}$ \\
\hline Chipre & 858.000 & 15,80 & 18,41 & 34.030 & 0,607 & 1,0 & 0,0 & 1,0 & $\begin{array}{c}0,42 \\
9\end{array}$ \\
\hline Croácia & 4.225 .316 & 40,82 & 9,66 & 22.740 & 0,964 & 1,0 & 1,0 & 1,0 & $\begin{array}{c}0,85 \\
7\end{array}$ \\
\hline Dinamarca & 5.659 .715 & 97,12 & 17,16 & 53.623 & 0,411 & 0,0 & 0,0 & 1,0 & $\begin{array}{c}0,64 \\
3 \\
\end{array}$ \\
\hline $\begin{array}{c}\text { Escócia- } \\
\text { UK }\end{array}$ & 5.347 .600 & -- & -- & 42.501 & 0,179 & 0,0 & 0,0 & 0,0 & $\begin{array}{c}0,71 \\
4\end{array}$ \\
\hline Eslováquia & 5.421 .349 & 70,10 & 12,93 & 28.060 & 0,982 & 1,0 & 1,0 & 1,0 & $\begin{array}{c}0,92 \\
9\end{array}$ \\
\hline Eslovênia & 2.061 .085 & 17,56 & 8,52 & 31.368 & 0,929 & 1,0 & 1,0 & 1,0 & $\begin{array}{c}0,71 \\
4\end{array}$ \\
\hline
\end{tabular}


LIMAS TOMIO, Fabrício Ricardo de; ROBL FILHO, Ilton Norberto. Autonomia e prerrogativas do ministério público brasileiro em perspectiva comparada: construindo um índice de independência/autonomia. Revista Eletrônica Direito e Política, Programa de Pós-Graduação Stricto Sensu em Ciência Jurídica da UNIVALI, Itajaí, v.16, n.3, 30 quadrimestre de 2021. Disponível em: www.univali.br/direitoepolitica ISSN 1980-7791.

\begin{tabular}{|c|c|c|c|c|c|c|c|c|c|}
\hline Espanha & 46.439 .864 & 270,48 & 5,82 & 47.494 & 0,946 & 1,0 & 1,0 & 1,0 & $\begin{array}{c}0,78 \\
6 \\
\end{array}$ \\
\hline Estônia & 1.313 .271 & 10,63 & 8,09 & 22.440 & 0,946 & 1,0 & 1,0 & 1,0 & $\begin{array}{c}0,78 \\
6\end{array}$ \\
\hline Finlândia & 5.471 .753 & 46,22 & 8,45 & 48.619 & 0,625 & 0,0 & 1,0 & 1,0 & $\begin{array}{c}0,50 \\
0\end{array}$ \\
\hline França & 66.317 .994 & 780,76 & 11,77 & 41.552 & 0,750 & 0,0 & 1,0 & 1,0 & $\begin{array}{c}1,00 \\
0\end{array}$ \\
\hline Geórgia & 3.729 .500 & 13,50 & 3,62 & 9.996 & 0,679 & 0,0 & 1,0 & 1,0 & $\begin{array}{c}0,71 \\
4\end{array}$ \\
\hline Grécia & 10.846 .979 & -- & -- & 30.159 & 0,839 & 0,5 & 1,0 & 1,0 & $\begin{array}{c}0,85 \\
7\end{array}$ \\
\hline Holanda & 16.902 .146 & 568,73 & 33,65 & 81.162 & 0,464 & 0,0 & 0,0 & 1,0 & \begin{tabular}{|c|}
0,85 \\
7 \\
\end{tabular} \\
\hline Hungria & 9.855 .571 & 119,74 & 12,15 & 16.217 & 0,750 & 1,0 & 0,0 & 1,0 & $\begin{array}{c}1,00 \\
0\end{array}$ \\
\hline $\begin{array}{c}\text { Inglaterra } \\
\text {-UK }\end{array}$ & 57.408 .654 & 854,56 & 14,89 & -- & 0,625 & 1,0 & 0,0 & 1,0 & $\begin{array}{c}0,50 \\
0 \\
\end{array}$ \\
\hline Irlanda & 4.625 .885 & 37,81 & 8,17 & 30.218 & 0,875 & 1,0 & 1,0 & 1,0 & $\begin{array}{c}0,50 \\
0\end{array}$ \\
\hline $\begin{array}{l}\text { Irlanda do } \\
\text { Norte-UK }\end{array}$ & 1.840 .498 & -- & -- & -- & 0,375 & 1,0 & 0,0 & 0,0 & $\begin{array}{c}0,50 \\
0 \\
\end{array}$ \\
\hline Israel & 8.296 .600 & -- & -- & 22.924 & 0,286 & 0,0 & 0,0 & 0,5 & $\begin{array}{c}0,64 \\
3\end{array}$ \\
\hline Itália & 60.795 .612 & $\begin{array}{c}1.460,3 \\
7\end{array}$ & 24,02 & 56.263 & 0,893 & 1,0 & 1,0 & 1,0 & $\begin{array}{c}0,57 \\
1 \\
\end{array}$ \\
\hline Letônia & 2.001 .468 & 21,77 & 10,88 & 19.369 & 0,982 & 1,0 & 1,0 & 1,0 & $\begin{array}{c}0,92 \\
9\end{array}$ \\
\hline Lituânia & 2.921 .262 & 28,56 & 9,78 & 16.195 & 0,732 & 1,0 & 0,0 & 1,0 & $\begin{array}{c}0,92 \\
9\end{array}$ \\
\hline $\begin{array}{c}\text { Luxembur } \\
\text { go }\end{array}$ & 563.000 & -- & -- & 75.316 & 0,750 & 1,0 & 0,0 & 1,0 & $\begin{array}{c}1,00 \\
0 \\
\end{array}$ \\
\hline Macedônia & 2.069 .172 & 6,50 & 3,14 & 17.719 & 0,661 & 0,0 & 1,0 & 1,0 & $\begin{array}{c}0,64 \\
3\end{array}$ \\
\hline Malta & 429.344 & -- & -- & 30.628 & 0,357 & 0,0 & 0,0 & 1,0 & $\begin{array}{c}0,42 \\
9\end{array}$ \\
\hline Moldova & 3.555 .159 & 8,34 & 2,35 & 3.217 & 0,696 & 1,0 & 0,0 & 1,0 & $\begin{array}{c}0,78 \\
6 \\
\end{array}$ \\
\hline Mônaco & 37.800 & 1,36 & 35,92 & 46.226 & 0,500 & 0,0 & 0,0 & 1,0 & $\begin{array}{c}1,00 \\
0 \\
\end{array}$ \\
\hline $\begin{array}{c}\text { Montenegr } \\
0 \\
\end{array}$ & 620.029 & 5,18 & 8,35 & 18.453 & 0,946 & 1,0 & 1,0 & 1,0 & \begin{tabular}{|c|}
0,78 \\
6 \\
\end{tabular} \\
\hline Noruega & 5.165 .802 & 20,82 & 4,03 & -- & 0,911 & 1,0 & 1,0 & 1,0 & $\begin{array}{c}0,64 \\
3\end{array}$ \\
\hline
\end{tabular}


LIMAS TOMIO, Fabrício Ricardo de; ROBL FILHO, IIton Norberto. Autonomia e prerrogativas do ministério público brasileiro em perspectiva comparada: construindo um índice de independência/autonomia. Revista Eletrônica Direito e Política, Programa de Pós-Graduação Stricto Sensu em Ciência Jurídica da UNIVALI, Itajaí, v.16, n.3, 30 quadrimestre de 2021. Disponível em: www.univali.br/direitoepolitica ISSN 1980-7791.

\begin{tabular}{|c|c|c|c|c|c|c|c|c|c|}
\hline Polônia & 38.496 .000 & 437,42 & 11,36 & 20.849 & $\mathbf{0 , 7 1 4}$ & 1,0 & 0,0 & 1,0 & $\begin{array}{c}0,85 \\
7\end{array}$ \\
\hline Portugal & 10.374 .822 & 88,79 & 8,56 & 35.699 & $\mathbf{0 , 9 8 2}$ & 1,0 & 1,0 & 1,0 & $\begin{array}{c}0,92 \\
9\end{array}$ \\
\hline $\begin{array}{c}\text { República } \\
\text { Tcheca }\end{array}$ & 10.524 .783 & 85,21 & 8,10 & 25.124 & $\mathbf{0 , 7 1 4}$ & 1,0 & 0,0 & 1,0 & $\begin{array}{c}0,85 \\
7\end{array}$ \\
\hline Romênia & 22.279 .183 & 238,80 & 10,72 & 23.676 & $\mathbf{0 , 8 3 9}$ & 0,5 & 1,0 & 1,0 & $\begin{array}{c}0,85 \\
7\end{array}$ \\
\hline Rússia & $\begin{array}{c}146.267 .28 \\
8\end{array}$ & $\begin{array}{c}1.346,5 \\
8\end{array}$ & 9,21 & -- & $\mathbf{0 , 4 4 6}$ & 1,0 & 0,0 & 0,0 & $\begin{array}{c}0,78 \\
6\end{array}$ \\
\hline Sérvia & 7.114 .393 & 35,55 & 5,00 & 17.728 & $\mathbf{0 , 6 7 9}$ & 0,0 & 1,0 & 1,0 & $\begin{array}{c}0,71 \\
4\end{array}$ \\
\hline Suécia & 9.747 .355 & 138,46 & 14,20 & 61.480 & $\mathbf{0 , 6 6 1}$ & 0,0 & 1,0 & 1,0 & $\begin{array}{c}0,64 \\
3\end{array}$ \\
\hline Suíça & 8.237 .666 & 539,21 & 65,46 & 116.230 & $\mathbf{0 , 1 7 9}$ & 0,0 & 0,0 & 0,0 & $\begin{array}{c}0,71 \\
4\end{array}$ \\
\hline Turquia & 77.695 .904 & -- & -- & 21.108 & $\mathbf{0 , 4 4 6}$ & 0,0 & 0,0 & 1,0 & $\begin{array}{c}0,78 \\
6\end{array}$ \\
\hline Ucrânia & 42.929 .000 & -- & -- & 5.094 & $\mathbf{0 , 8 0 4}$ & 1,0 & 1,0 & 0,5 & $\begin{array}{c}0,71 \\
4\end{array}$ \\
\hline
\end{tabular}

(*) Dados para o Brasil de 2015. CNMP (Conselho Nacional do Ministério Público). Demais países CEPEJ (2016). Conversão R\$ para $€$, cotação média BCB-Banco Central do Brasil, 2015/2017.

$(* *)$ (1) Status of public prosecutors - Statutorily independente; (2) Regulation to prevent specific instructions to prosecute or not, addressed to a prosecutor in a court?; (3) Term of office of prosecutors (Mandate); (4) Role of public prosecutor (CEPEJ, 2016, p. 114, 118 e 124). Fonte: Dados para o Brasil definidos pelos pesquisadores do Núcleo de Pesquisa DIRPOL/PPGD/UFPR com base na constituição e legislação. Dados dos países europeus: (CEPEJ; 2016). https://rm.coe.int/european-judicial-systems-efficiency-and-quality-of-justice-cepejstud/1680786b58. 